

\title{
Modelling the mobile target covering problem using flying drones
}

\author{
Luigi Di Puglia Pugliese, Francesca Guerriero, Dimitrios Zorbas, Tahiry \\ Razafindralambo
}

\section{- To cite this version:}

Luigi Di Puglia Pugliese, Francesca Guerriero, Dimitrios Zorbas, Tahiry Razafindralambo. Modelling the mobile target covering problem using flying drones. Optimization Letters, 2016, 10 (5), pp.29. 10.1007/s11590-015-0932-1 . hal-01187118

\section{HAL Id: hal-01187118 https://hal.inria.fr/hal-01187118}

Submitted on 26 Aug 2015

HAL is a multi-disciplinary open access archive for the deposit and dissemination of scientific research documents, whether they are published or not. The documents may come from teaching and research institutions in France or abroad, or from public or private research centers.
L'archive ouverte pluridisciplinaire HAL, est destinée au dépôt et à la diffusion de documents scientifiques de niveau recherche, publiés ou non, émanant des établissements d'enseignement et de recherche français ou étrangers, des laboratoires publics ou privés. 


\title{
Modelling the mobile target covering problem using flying drones
}

\author{
Luigi Di Puglia Pugliese ${ }^{1 *} \quad$ Francesca Guerriero $^{1 \dagger} \quad$ Dimitrios Zorbas $^{2} \ddagger$ \\ Tahiry Razafindralambo ${ }^{\S}$ \\ ${ }^{1}$ Department of Mechanics, Energy and Management Engineering, University of Calabria, 87036, Rende (CS), \\ Italy. \\ ${ }^{2}$ Inria Lille - Nord Europe - France
}

\begin{abstract}
This paper addresses the mobile targets covering problem by using unmanned aerial vehicles (UAVs). It is assumed that each UAV has a limited initial energy and the energy consumption is related to the UAV's altitude. Indeed, the higher the altitude, the larger the monitored area and the higher the energy consumption. When an UAV runs out of battery, it is replaced by a new one. The aim is to locate UAVs in order to cover the piece of plane in which the target moves by using a minimum number of UAVs. Each target has to be monitored for each instant time. The problem under consideration is mathematically represented by defining mixed integer non-linear optimization models. Heuristic procedures are defined and they are based on restricted mixed integer programming (MIP) formulation of the problem. A computational study is carried out to assess the behaviour of the proposed models and MIP-based heuristics. A comparison in terms of efficiency and effectiveness among models and heuristics is carried out.
\end{abstract}

Keywords: targets tracking; unmanned aerial vehicles; non-linear programming; matheuristic.

\section{Introduction}

Emerging pervasive application systems, such as observation and tracking of unknown objects, will face a number of challenges, including the need to operate in extreme and unknown environments. Examples of applications, arising in these environments, include emergency response and disaster recovery, environmental monitoring and vehicular networks.

In this paper, we consider the specific scenario where targets (points that have to be monitored such as vehicles, animals, humans) are mobile and little a-priori information about their

\footnotetext{
*luigi.dipugliapugliese@unical.it

${ }^{\dagger}$ francesca.guerriero@unical.it

${ }^{\ddagger}$ dimitrios.zormpas@inria.fr

${ }^{\S}$ tahiry.razafindralambo@inria.fr
} 
mobility is known. It is then critical to design efficient algorithms and schemes to support pervasive, "any time, any place" services and coverage in these highly mobile environments, prone to time and space evolution. This represents a fairly complex point of interest in coverage problems and constitutes the main focus of this paper.

In particular, we handle the optimal deployment of unmanned aerial vehicles (UAVs) to cover a set of targets. Our aim is to ensure that each mobile target is covered by at least one UAV. We also add another dimension in our problem, that is, each UAV can change its observation (coverage) radius, depending on its altitude that allows it to cover more or less targets. In addition, it is assumed that the energy consumed by each UAV is related to its altitude and when an UAV runs out of battery, it is replaced by a new one. Our objective is to minimize the number of used UAVs to cover all the targets. The number of UAVs depends on the number of targets, their dispersion, their movement but also on the energy consumed by each UAV. To the best of our knowledge, this is one of the first papers that specifically deals with energy efficiency and mobile target tracking in the context of UAVs.

In the application under consideration, it is important to improve the reliability of the system by providing the most appropriate and up to date information, at the lowest cost (i.e., minimizing the number of UAVs).

A simplified version of the considered problem has been addressed by the same authors in [29], where it is assumed that an infinite number of UAVs is available and when an UAV moves to another position, it is replaced by another one. In [29], the objective is to minimize the total energy consumption. In this paper, we handle a more realistic aspect of the problem under study. Indeed, we assume that the initial energy of each UAV is not enough for monitoring the targets and we model the possibility of substituting an UAV that runs out of battery with another one, by introducing non-linear constraints in the mathematical formulation. We consider two different situations: a) an UAV is replaced by another flying drone with the same initial energy; b) an UAV with a different initial energy is used. The introduction of non-linear restrictions makes the resulting optimization models (mixed integer non-linear programs) more complex than the one presented in [29].

It is worth observing that this work has the aspiration to provide a new starting point on the field of mobile targets tracking problem with UAVs. Indeed, we introduce the problem, give mathematical formulations and show that the problem is very hard to solve under optimization perspective. As highlighted hereafter, simulations and heuristic procedures are mandatory for addressing the problem under study.

The remainder of the paper is organized as follows. In section 2, we discuss the related works. Section 3 introduces the optimization models, whereas the proposed heuristics are presented in section 4. Section 5 is devoted to the presentation of the computational results collected to assess the behavior of the proposed models and heuristics in terms of correctness and efficiency. A detailed accounting of the numerical results is reported in the appendix. The paper ends with some conclusions given in section 6 . 


\section{Related Work}

Target detection and UAVs cooperation have been studied by many different viewpoints. Reviewing the corresponding scientific literature, one could divide the research contributions in two main groups. The former includes papers that are related to the computation of an optimal trajectory, along which a number of tasks must be carried out; the latter includes works where UAVs are used to maximize the coverage of either an area or specific targets.

The objectives may vary depending on the characteristics of the application (i.e., knowledge of the position of the targets, number of robots, full or partial coverage of the area). However, most of the scientific contributions deal with the minimization of a single criterion such as (a) the average time between the appearance of an event and the time in which the UAVs complete the coverage task [10], (b) the total length of the trajectory [4], and (c) the service cost [22].

In many cases, the optimal trajectory planning problems are mathematically represented as dynamic vehicle routing models. In the classical vehicle routing problems, the position of the targets is advertised to the vehicles. However, in many real applications this information is not known and, thus, the UAVs must be equipped with search or patrol capabilities [5]. In [6], an automated surveillance system for tracking multiple mobile ground targets is proposed. The objective of the approach is to find the position of the targets and minimize the total energy cost. Works related to task allocation and trajectory planning are also presented in $[1,20,26]$.

Apart from the problems where the UAVs are scheduled to follow a trajectory with a minimum cost, a relevant part of the published papers is dedicated to coverage requirements and mainly to how well targets can be tracked by sensors (e.g cameras) attached to the UAVs. In [12] an algorithm to cooperatively track a moving target by several UAVs is proposed. The objective is to keep the target in the sight of the cameras from different angles, by ensuring a low computation complexity. A multi-criteria version of the problem, in which the total distances traveled by the UAVs, the customer satisfaction and the number of used UAVs are considered simultaneously, has been addressed in [9]. In [21] a similar problem is considered where a group of UAVs detects the position of targets using sensors located on the vehicles. Real vision-based UAV navigation and guidance systems are presented in $[3,24]$. Detection problems are also studied in $[23,28]$.

Communication between UAVs can improve the location estimation of mobile targets and the robustness of the system [18]. In [19], a team of UAVs has been used to simulate a cooperative moving target engagement scenario, with the team acting as a sensor and communication network to cooperatively track and attack moving ground targets. Cooperative search and coverage is the objective of $[14,15,17]$. Algorithms are proposed to decide the area to segments and vehicles are used to cooperatively monitor the segments.

Despite the recent extensive research work on target tracking and UAV cooperation, energy efficiency is not well studied. Only a few scientific works are more focused on the computation of energy efficient trajectories $[11,16]$ rather than on the target-following problem where UAVs follow the targets as long as they are in their field of vision. 


\section{Mathematical Formulation}

The mobile targets covering problem, addressed in this paper, can be defined as follows. We assume the availability of a set of UAVs that are equipped with a camera to detect and follow mobile targets.

A little a-priori information about the position of the targets and their mobility is known. In order to model the problem, we consider a possible scenario in which it is assumed that an estimate of the position of each target is available for each instant time. The scenario is generated by taking into account the available information. Thus, the proposed mathematical model provides a solution to a simplified version of the problem that can be used as starting point in order to plan the displacement of the UAVs and their number. In a real application, the solution provided by the model can be adjusted whenever the real position of some targets differs from that of the scenario considered.

The camera has a maximum vision angle and a maximum range beyond which the robot cannot accurately detect the targets. The detection area of each UAV is circular. Each UAV has a limited initial energy and it is replaced by another flying drone, when it runs out of energy. The UAVs can fly at different altitude, providing different observation radius. The higher a UAV flies, the more energy it consumes. The objective is to constantly cover all the targets while minimizing the number of used UAVs.

In order to describe the proposed mathematical models, it is useful to introduce the following notations. Let $L$ be the set of available UAVs and $\Delta$ be the set of targets that have to be monitored. Each target $\delta \in \Delta$ can move in any direction in two dimensional space (i.e., in the $\mathrm{X}-\mathrm{Y}$ plane) and the position of $\delta$ is represented by the coordinates $\left(X_{\delta}, Y_{\delta}\right)$. A time windows $\left[t_{\text {min }}^{\delta}, t_{\text {max }}^{\delta}\right]$ is associated with each target $\delta \in \Delta$. This means that the target $\delta$, initially located at the point of coordinates $\left(X_{\delta}, Y_{\delta}\right)$ must be observed in the time range defined by the corresponding time window.

In order to represent the movement, target $\delta$ is replaced with $|C|$ copies. A time window is associated with each copy $\delta_{j}, j=1, \ldots|C|$ of target $\delta$. In particular, $\left[t_{\text {min }}^{\delta}, t_{\text {min }}^{\delta}+\tau\right]$ is the time window associated with the first copy of $\delta$, whereas the time window associated with the copy $\delta_{j+1}, j=1, \ldots,|C|$, is defined as $\left[t_{\text {max }}^{\delta_{j}}, t_{\text {max }}^{\delta_{j}}+\tau\right]$. Of course, if the computed time window for the last copy of the target $\delta$ exceeds the given value $t_{\text {max }}^{\delta}$, that is, the condition $t_{\text {max }}^{\delta_{|C|}}>t_{\text {max }}^{\delta}$ is verified, then $t_{\text {max }}^{\delta_{|C|}}=t_{\text {max }}^{\delta}$. The target and its copies are stored in the set $\dot{\Delta}$.

Each UAV $l \in L$ can be located in a 3 -dimensional space and $(i, j, k)$ represents its position, where $i$ and $j$ are the component on the $\mathrm{X}-\mathrm{Y}$ plane, while $k$ is the altitude. UAV $l$ has a visibility represented by a circle in the plane with radius $r_{l}^{k}$. The higher the value of $k$, the longer the radius. In addition, each UAV $l \in L$ consumes $E^{l}=(\beta+\alpha k) t+P_{\max }(k / s)$ energy, where $\beta$ is the minimum power needed to hover just over the ground (when altitude is almost zero) and $\alpha$ is a motor speed multiplier. Both $\beta$ and $\alpha$ depend on the weight and motor/propeller characteristics. $P_{\max }$ is the maximum power of the motor, $s$ is the speed, $t$ is the operating time and the target $l$ has an initial energy equals to $E_{I}^{l}$. The term $P_{\max }(k / s)$ refers to the power consumption needed to lift to height $k$ with speed $s$. According to our own measurements with 
mobile robots and drone manufacturers specifications, we presume that this power consumption model is not far from the reality. For more details on the proposed energy consumption model, the reader is referred to [27].

We define as $D_{\delta}^{l}$ the projection on the $\mathrm{X}-\mathrm{Y}$ plane of the distance between the UAV $l$, positioned at coordinates $(i, j, k)$, and the target $\delta$, that is, $D_{\delta}^{l}=\sqrt{\left(X_{\delta}-i\right)^{2}+\left(Y_{\delta}-j\right)^{2}}$.

In order to present the mathematical formulation of the problem at hand, we introduce the binary variable $x_{i j k}^{l}$ that takes the value of 1 if the UAV $l$ is located in position $(i, j, k), 0$ otherwise; the binary variable $y_{\delta}^{l}$ that takes value equal to 1 if the target $\delta$ is observed by the $\mathrm{UAV} l, 0$ otherwise.

In the first formulation of the problem, we assume that each UAV $l \in L$ can be replaced by an identical one, that is, with the same radius of visibility and the same initial energy. Let $\gamma_{l}$ be the decision variable that indicates the number of UAVs that replace $l$ plus $l$ itself, that are needed to monitor at least one target. Let $t_{\text {start }}^{l}$ and $t_{\text {end }}^{l}$ be the initial and final time of observation of such UAVs, respectively.

The objective is to monitor all targets $\delta \in \dot{\Delta}$ for $t_{\text {max }}^{\delta}-t_{\text {min }}^{\delta}$ units of time and the total number of UAVs is minimized. The problem can be mathematically formulated by the mixed integer non-linear program (1) - (9) below.

$$
\min \sum_{l \in L} \gamma_{l}
$$

s.t.

$$
\begin{aligned}
& \sum_{(i, j, k) \in \mathbb{R}^{3}} x_{i j k}^{l} \leq 1 \quad \forall l \in L, \\
& y_{\delta}^{l} \leq \sum_{(i, j, k) \in \mathbb{R}^{3}} x_{i j k}^{l}\left(\frac{r_{l}^{k}}{D_{\delta}^{l}}\right) \quad \forall l \in L, \delta \in \dot{\Delta} \\
& \sum_{l \in L} y_{\delta}^{l} \geq 1 \quad \forall \delta \in \dot{\Delta} \\
& t_{\text {start }}^{l} \leq t_{\text {min }}^{\delta} y_{\delta}^{l}+M\left(1-y_{\delta}^{l}\right) \quad \forall l \in L, \delta \in \dot{\Delta}, \\
& t_{\text {start }}^{l} \leq \sum_{\delta \in \dot{\Delta}} t_{\text {min }}^{\delta} y_{\delta}^{l} \quad \forall l \in L, \\
& t_{\text {end }}^{l} \geq t_{\text {max }}^{\delta} y_{\delta}^{l} \quad \forall l \in L, \delta \in \dot{\Delta}, \\
& \gamma_{l} \geq \frac{1}{E_{I}^{l}}\left[\left(\beta+\alpha \quad \sum_{(i, j, k) \in \mathbb{R}^{3}} k x_{i j k}^{l}\right)\left(t_{\text {end }}^{l}-t_{\text {start }}^{l}\right)+\frac{P_{\text {max }}}{s} \sum_{(i, j, k) \in \mathbb{R}^{3}} k x_{i j k}^{l}\right] \quad \forall l \in L, \\
& x_{i j k}^{l} \in\{0,1\}, \forall(i, j, k) \in \mathbb{R}^{3}, l \in L ; y_{\delta}^{l} \in\{0,1\}, \forall \delta \in \dot{\Delta}, l \in L ; \\
& t_{\text {start }}^{l}, t_{\text {end }}^{l} \in \mathbb{R}, \gamma_{l} \in \mathbb{N}, \forall l \in L .
\end{aligned}
$$


Equation (1) means that the total number of UAVs must be minimized. Equations (2) ensure that the UAV $l$ is located in at most one position. Equations (3) define the value of variables $y_{\delta}^{l}$. In particular, if the radius is less than the distance, then $y_{\delta}^{l}$ takes value equals to 0 , otherwise, the variable can assume values equals to 0 or 1 . Constraints (4) ensure that each target is observed by at least one UAV. Equations (5), (6) and (7) define the initial and final time of observation of UAV $l$, respectively, where $M=\max _{\delta \in \dot{\Delta}}\left\{t_{\min }^{\delta}\right\}$. Constraints (8) set the variables $\gamma_{l}$ equal to the number of UAVs that replace $l$ plus $l$ itself. Equations (9) define the domain of the decision variables.

It is possible to consider also the case in which the UAV can be replaced by other one, with different characteristic in terms of initial energy. In this respect, we consider several types of UAVs. In order to give the mathematical formulation of this second version of the problem, let $O$ be the set of all available UAV's typologies. Each typology has a different initial energy denoted by $E_{I}^{o}$.

We define the variable $u_{o}^{l} \in \mathbb{Z}$ that counts the number of UAVs of type $o \in O$ that replaces the UAV $l \in L$. The mixed integer non-linear model (10) - (18) represents this second version of the problem.

$$
\min \sum_{(i, j, k) \in \mathbb{R}^{3}} \sum_{l \in L} x_{i j k}^{l}+\sum_{o \in O} \sum_{l \in L} u_{0}^{l}
$$

s.t.

$$
\begin{aligned}
& \sum_{(i, j, k) \in \mathbb{R}^{3}} x_{i j k}^{l} \leq 1 \quad \forall l \in L, \\
& y_{\delta}^{l} \leq \sum_{(i, j, k) \in \mathbb{R}^{3}} x_{i j k}^{l}\left(\frac{r_{l}^{k}}{D_{\delta}^{l}}\right) \quad \forall l \in L, \delta \in \dot{\Delta}, \\
& \sum_{l \in L} y_{\delta}^{l} \geq 1 \quad \forall \delta \in \dot{\Delta}, \\
& t_{\text {start }}^{l} \leq t_{\text {min }}^{\delta} y_{\delta}^{l}+M\left(1-y_{\delta}^{l}\right) \quad \forall l \in L, \delta \in \dot{\Delta}, \\
& t_{\text {start }}^{l} \leq \sum_{\delta \in \dot{\Delta}} t_{\text {min }}^{\delta} y_{\delta}^{l} \quad \forall l \in L, \\
& t_{\text {end }}^{l} \geq t_{\text {max }}^{\delta} y_{\delta}^{l} \quad \forall l \in L, \delta \in \dot{\Delta}, \\
& \sum_{o \in O} E_{I}^{o} u_{o}^{l} \geq\left(\beta+\alpha \quad \sum_{(i, j, k) \in \mathbb{R}^{3}} k x_{i j k}^{l}\right)\left(t_{\text {end }}^{l}-t_{\text {start }}^{l}\right)+\frac{P_{\text {max }}}{s} \sum_{(i, j, k) \in \mathbb{R}^{3}} k x_{i j k}^{l}-E_{I}^{l} \\
& \forall l \in L, \quad \forall(i, j, k) \in \mathbb{R}^{3}, l \in L ; y_{\delta}^{l} \in\{0,1\}, \forall \delta \in \dot{\Delta}, l \in L ; \\
& x_{i j k}^{l} \in\{0,1\}, \\
& t_{\text {start }}^{l}, t_{\text {end }}^{l}, \in \mathbb{R}, \forall l \in L ; u_{o}^{l} \in \mathbb{Z}, \forall l \in L, o \in O .
\end{aligned}
$$


The objective function (10) counts the total number of UAVs that are used for monitoring the targets. Constraints (17) define the number of UAVs of type $o$ required to cover all targets $\delta$ originally monitored by $l$. This model provides the position of each UAV $l$ and the targets $\delta$ that are covered by the UAVs. In addition, the model gives the type and the number of UAVs that replace each UAV $l$, when it runs out of battery. The objective is to minimize the total number of active UAVs.

Minimizing the number of activated UAVs implied that the chosen typology is that with the highest initial energy. Indeed, given an energy consumption, the higher $E_{I}^{o}$, the lower the number of UAVs of typology o needed to cover the monitored targets. An interesting variant of model (10) - (18) considers activation cost associated with each typology $o \in O$. The higher the initial energy, the higher the activation cost. Let $c_{o}$ be the cost for activating the UAVs of typology $o \in O$, the objective function (10) assumes the following form

$$
\sum_{o \in O} \sum_{l \in L} c_{o} u_{o}^{l}
$$

Both model (1) - (9) and (10) - (18) presents non-linear constraints related to the energy consumption. In particular, the term $\sum_{(i, j, k) \in \mathbb{R}^{3}} k x_{i j k}^{l}\left(t_{\text {end }}^{l}-t_{\text {start }}^{l}\right)$ in constraints (8) and (17) makes the models mixed integer non-linear formulations. The problems can be linearized introducing variables $s_{i j k}^{l}$ and $e_{i j k}^{l}$ and the following constraints

$$
\begin{aligned}
& s_{i j k}^{l} \leq t_{\text {start }}^{l}, \forall(i, j, k) \in \mathbb{R}^{3}, l \in L, \\
& s_{i j k}^{l} \leq M x_{i j k}^{l}, \forall(i, j, k) \in \mathbb{R}^{3}, l \in L, \\
& s_{i j k}^{l} \geq t_{\text {start }}^{l}+M\left(x_{i j k}^{l}-1\right), \forall(i, j, k) \in \mathbb{R}^{3}, l \in L, \\
& e_{i j k}^{l} \leq t_{\text {end }}^{l}, \quad \forall(i, j, k) \in \mathbb{R}^{3}, l \in L, \\
& e_{i j k}^{l} \leq M_{1} x_{i j k}^{l}, \quad \forall(i, j, k) \in \mathbb{R}^{3}, l \in L, \\
& e_{i j k}^{l} \geq t_{\text {end }}^{l}+M_{1}\left(x_{i j k}^{l}-1\right), \quad \forall(i, j, k) \in \mathbb{R}^{3}, l \in L,
\end{aligned}
$$

where $M_{1}=\max _{\delta \in \dot{\Delta}}\left\{t_{\text {max }}^{\delta}\right\}$. Using variables $s_{i j k}^{l}$ and $e_{i j k}^{l}$, the energy consumption $E^{l}=$ $\left(\beta+\alpha \sum_{(i, j, k) \in \mathbb{R}^{3}} k x_{i j k}^{l}\right)\left(t_{\text {end }}^{l}-t_{\text {start }}^{l}\right)+\frac{P_{\max }}{v} \sum_{(i, j, k) \in \mathbb{R}^{3}} k x_{i j k}^{l}$, for each UAV $l \in L$ is linearized and takes the following form

$$
E^{l}=\beta\left(t_{\text {end }}^{l}-t_{\text {start }}^{l}\right)+\alpha\left(\sum_{(i, j, k) \in \mathbb{R}^{3}} k e_{i j k}^{l}-\sum_{(i, j, k) \in \mathbb{R}^{3}} k s_{i j k}^{l}\right)+\frac{P_{\text {max }}}{v} \sum_{(i, j, k) \in \mathbb{R}^{3}} k x_{i j k}^{l} .
$$


It is worth observing that the LP-relaxations of the above formulations can be strengthened by adding the following (redundant) constraints.

$$
\begin{aligned}
& t_{\text {end }}^{l} \leq \max _{\delta \in \dot{\Delta}}\left\{t_{\text {max }}^{\delta}\right\}, \quad \forall l \in L, \\
& t_{\text {start }}^{l} \leq t_{\text {end }}^{l}, \quad \forall l \in L, \\
& \sum_{(i, j, k) \in \mathbb{R}^{3}} \sum_{l \in L} x_{i j k}^{l} \leq|\dot{\Delta}|, \\
& \sum_{l \in L} \sum_{k \in \mathbb{R}} x_{i j k}^{l} \leq 1, \quad \forall(i, j) \in \mathbb{R}^{2}, \\
& \sum_{\delta \in \dot{\Delta}} \sum_{l \in L} y_{\delta}^{l} \geq|\dot{\Delta}|, \\
& \sum_{l \in L} x_{i j k}^{l} \leq 1, \quad \forall(i, j, k) \in \mathbb{R}^{3} .
\end{aligned}
$$

Indeed, during the computational phase we have observed that the computational time and the number of iterations performed by the solver are drastically reduced when constraints (27) - (32) are considered. This behaviour is related to the fact that better bounds are available at each node of the branch-and-bound procedure.

\section{MIP-based Heuristic}

The proposed models are very hard to solve to optimality due to the high computational complexity (see Section 5). For this reason, heuristic procedure is mandatory in order to obtain satisfactory solution within a reasonable amount of time.

In this Section, we present a MIP-based heuristic. The proposed solution strategy is an iterative procedure, whose main idea is to consider, at each step, a subset of targets to be monitored, which is enlarged at each iteration. The subproblems are easier to solve than the entire problem and the solution obtained at some iteration is built by considering the decisions taken in the previous ones.

The proposed heuristic procedure iteratively solves restricted MIP problems. In particular, we consider a partition of the set $\dot{\Delta}$ in $N$ subsets $\dot{\Delta}_{n}$, such that $\bigcup_{n=1}^{N} \dot{\Delta}_{n}=\dot{\Delta}$ and $\bigcap_{n=1}^{N} \dot{\Delta}_{n}=\emptyset$. The MIP-based heuristic solves the problems (1) - (9) and (10) - (18) at each iteration $n$, considering the set $\dot{\Delta}_{n}$ and taking into account the solution determined in the previous iteration.

Let $(l, i, j, k)^{n}$ be the tuples indicating that UAV $l$ has been allocated in position $(i, j, k)$ at iteration $n=1, \ldots, N$. The heuristic solves the problems (1) - (9) and (10) - (18) with the following constraints. 


$$
\begin{aligned}
& x_{i j k}^{l}=1, \quad \forall(l, i, j, k)^{n}, \\
& t_{\text {start }}^{l} \leq \bar{t}_{\text {start }}^{l, n} \quad \forall l: \exists(l, i, j, k)^{n}, \\
& t_{\text {end }}^{l} \geq \bar{t}_{\text {end }}^{l, n} \quad \forall l: \exists(l, i, j, k)^{n},
\end{aligned}
$$

where the parameters $\vec{t}_{\text {start }}^{l, n}$ and $\vec{t}_{\text {end }}^{l, n}$ are the values of variables $t_{\text {start }}^{l}$ and $t_{\text {end }}^{l}$, respectively, at iteration $n$. Constraints (6) and (15) are modified in order to take into account the solution of the previous iterations as follows

$$
t_{\text {start }}^{l} \leq \sum_{\delta \in \dot{\Delta}_{n+1}} t_{\text {min }}^{\delta} y_{\delta}^{l}+\min _{h=1, \ldots, n} \bar{t}_{\text {start }}^{l, h} \quad \forall l \in L
$$

For each iteration $n=2, \ldots, N$, variables $x$ for which the UAV $l$ has been located at position $(i, j, k)$ in iteration $n-1$ are fixed (see equation (33)). In addition, the time of observation of UAV $l$ is taken into account by adding constraints (34) - (35).

The effectiveness of the proposed heuristic is related to the structure of subsets $\dot{\Delta}_{n}$. Indeed, these subsets define the order in which the targets are processed. Several rules can be applied to construct $\dot{\Delta}_{n}, n=1, \ldots, N$. In this paper, we consider five versions of the MIP-based heuristic considering five different structures of $\dot{\Delta}_{n}, n=1, \ldots, N$, described in the following.

1. Each subset $\dot{\Delta}_{n}$ contains a target and its copies.

2. The targets are ordered in non-decreasing euclidean distance from a chosen initial target.

3. The targets are ordered in non-increasing width of the associated time windows.

4. The targets are ordered in non-decreasing width of the associated time windows.

5. The targets are ordered in non-decreasing values of $t_{\min }^{\delta}$.

For the versions $2-5$, each subset $n=1, \ldots, N-1$ contains $g$ targets, whereas $\left|\dot{\Delta}_{N}\right|=$ $|\dot{\Delta}|-g \times(N-1)$.

Example 1. Let us consider the scenario in Table 1 when solving model (1)-(9).

\begin{tabular}{l|rrrrrr}
\hline Target $\delta$ & $\mathrm{A}$ & $\mathrm{B}$ & $\mathrm{C}$ & $\mathrm{D}$ & $\mathrm{E}$ & $\mathrm{F}$ \\
\hline$X_{\delta}$ & 3 & 2 & 4 & 8 & 6 & 7 \\
$Y_{\delta}$ & 2 & 8 & 3 & 4 & 8 & 11 \\
$t_{\min }^{\delta}$ & 0 & 0 & 6 & 15 & 16 & 20 \\
$t_{\max }^{\delta}$ & 20 & 19 & 8 & 20 & 17 & 22 \\
\hline
\end{tabular}

Table 1: Information about the targets to be monitored. 
The set of available UAVs $L$ is composed of 6 elements (in the worst case the targets are monitored by different UAVs). Each UAV can be located at two altitude $k_{1}$ and $k_{2}$ with radius equal to 2 and 4 , respectively. We partition the set $\Delta$ applying the strategy 5 and letting $g=2$. In particular, $\dot{\Delta}_{1}=\{A, B\}, \dot{\Delta}_{2}=\{C, D\}$, and $\dot{\Delta}_{3}=\{E, F\}$.

Table 2 shows, for each iteration, the coordinates in which $U A V l$ is located, the values of $\vec{t}_{\text {start }}^{l, n} \vec{t}_{\text {end }}^{l, n}$ and the targets monitored by $l$.

\begin{tabular}{|c|c|c|c|c|}
\hline & & \multicolumn{3}{|c|}{ iteration } \\
\hline$l$ & & 1 & 2 & 3 \\
\hline 1 & $\begin{array}{l}(i, j, k) \\
\bar{t}_{\text {start }}^{1, n} \\
\bar{t}_{\text {end }}^{1, n} \\
\delta\end{array}$ & $\begin{array}{c}\left(2,5, k_{2}\right) \\
0 \\
20 \\
\mathrm{~A}, \mathrm{~B}\end{array}$ & $\begin{array}{c}\left(2,5, k_{2}\right) \\
0 \\
20 \\
\mathrm{C}\end{array}$ & \\
\hline 2 & $\begin{array}{l}(i, j, k) \\
\bar{t}_{\text {start }}^{2, n} \\
\vec{t}_{\text {end }}^{2, n} \\
\delta\end{array}$ & & $\begin{array}{c}\left(8,4, k_{1}\right) \\
15 \\
20 \\
\mathrm{D}\end{array}$ & \\
\hline 3 & $\begin{array}{l}(i, j, k) \\
\bar{t}_{\text {start }}^{3, n} \\
\bar{t}_{\text {end }}^{3, n} \\
\delta\end{array}$ & & & $\begin{array}{c}\left(6,10, k_{1}\right) \\
16 \\
22 \\
\mathrm{E}, \mathrm{F}\end{array}$ \\
\hline
\end{tabular}

Table 2: Results obtained by the proposed heuristic when solving the problem of Table 1 .

At the first iteration, model (1)-(9) is solved considering only targets $A$ and $B$, that is, the set $\dot{\Delta}_{1}$. The solution is shown in Figure $1(a)$ where the UAV 1 is activated. In particular, UAV 1 is located at coordinate $\left(2,5, k_{2}\right)$ and it is active from the instant time 0 to 20 (see the column referred to the first iteration of Table 2).

At the second iteration, UAV 1 covers also the new target $C$. The time of observation remain unchanged (second column of Table 2). For the target D, UAV 2 has to be activated (see Figure $1(b))$ in position $\left(8,4, k_{1}\right)$ from the instant time 15 to 20. When targets $D$ and $F$ are considered, none UAVs 1 and 2 are able to monitor them, thus, a new drone, UAV 3 is used from the instant time 16 to 22 and its position is $\left(6,10, k_{1}\right)$ (see the third column of Table 2). Figure 1(c) shows the deployment of the UAVs considering the data of Table 1 obtained with the proposed heuristic.

It is worth observing that the proposed heuristic can be adopted to solve the on-line version of the probelm. In other words, the position of the targets is not known in advance rather this information is available whenever the real position is detected. Starting from the known positions, the displacement of the UAVs is determined. When a new position is available, a new subproblem is solved by considering the current knowledge on the targets mobility. 


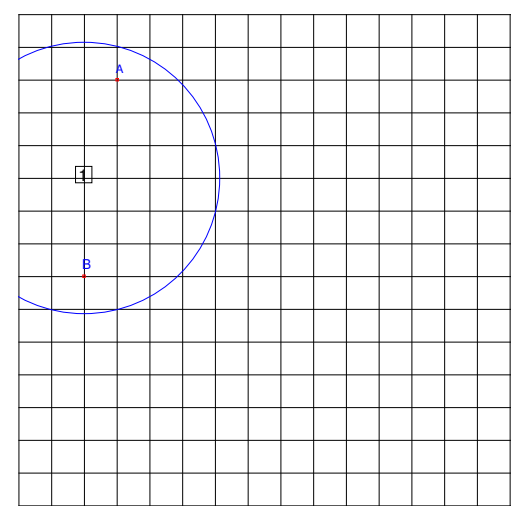

(a) Deployment of UAVs for $\dot{\Delta}_{1}$

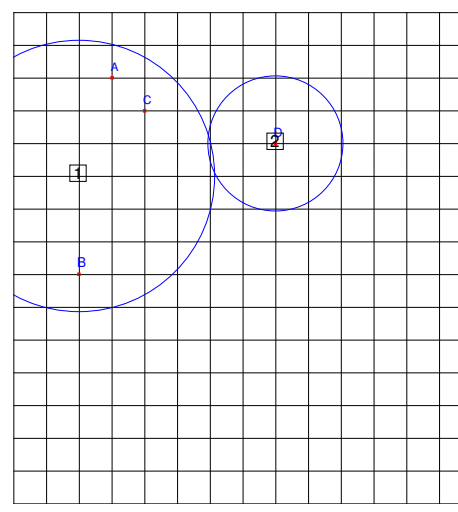

(b) Deployment of UAVs for $\dot{\Delta}_{2}$

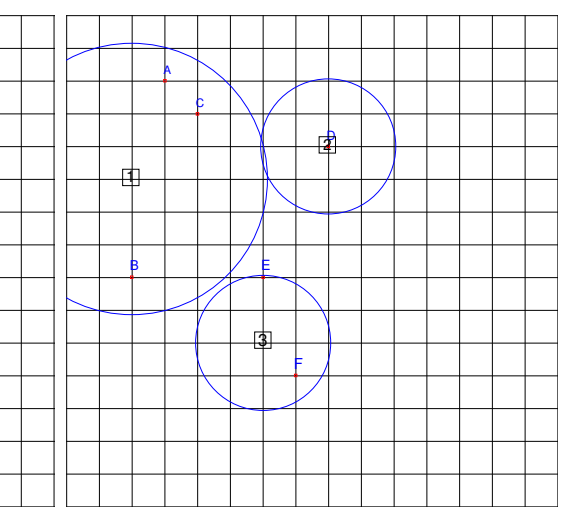

(c) Deployment of UAVs for $\dot{\Delta}_{3}$

Figure 1: The positions of the UAVs computed at each iteration of the heuristic.

\section{Computational Results}

The linearized models (1) - (9) and (10) - (18) and the MIP-based heuristics have been implemented in Java language and the mathematical formulations have been solved using Cplex 12.5.1. It is worth observing that in both models and MIP-based heuristics, constraints (27) (32) have been considered.

The implemented models are referred in the sequel as $M_{1}, M_{2}$, and $M_{c}$. In particular, $M_{1}$ is model (1) - (9), $M_{2}$ refers to model (10) - (18), $M_{c}$ is the model (10) - (18) with the cost-based objective function (19).

We refer to $M H_{1}^{v}, M H_{2}^{v}$, and $M H_{c}^{v}$, to indicate the MIP-based heuristics which solve model $M_{1}, M_{2}$, and $M_{c}$, respectively, considering the version $v=1, \ldots, 5$ defined in section 4 that differ on how the targets are processed. The parameter $g$ is set equal to two and it is the best trade-off between efficiency and effectiveness for the instances considered here.

The computational results are collected on an Intel(R) Core(TM) i7 CPU M 620, $2.67 \mathrm{GHz}$, 4 GB RAM machine, under Microsoft windows 7 operation system.

\subsection{Test Instances}

We have considered a $100 \times 100$ plane and three different altitudes $k \in\{1,5,10\}$. We generate three discretizations of the plane. In particular, the parameter $d$ is used to define the number of points in the plane in which an UAV can be placed. Given a value for $d$, each UAV could be located in one of the $\left(\frac{100}{d}+1\right) \times\left(\frac{100}{d}+1\right) \times k$ positions. In our experiments, we set $d=20,10,5$. Three different values of initial energy have been considered, that is, $E_{I}^{l}=\{300,600,900\}$. Considering model $M_{2}$ and $M_{c}$, two typologies of UAVs have been taken into account, they are characterized by initial energy $E_{I}^{o}=\{400,700\}$ and cost $c_{o}=\{1,3\}$. The parameters used to define the energy consumption are set to $\alpha=1, \beta=30, P_{\max }=85$ and $s=2$.

The number of targets $|\dot{\Delta}|$ belongs to the set $\{10,15,20,25,30\}$. It is worth observing that we 
have considered only one copy for each target, thus, $|\Delta| \in\{5,8,10,13,15\}$. The time windows $\left[t_{m i n}^{\delta}, t_{m a x}^{\delta}\right]$ are defined by randomly choosing $t_{\text {min }}^{\delta}$ and $t_{m a x}^{\delta}-t_{m i n}^{\delta}$. In particular, the initial of the time window and its width are set equal to values belonging to uniform distributions $[0,10]$ and $[0,20]$, respectively.

A total of 45 instances are generated. The characteristics of each instance in terms of $\dot{\Delta}$, $E_{I}^{l}$, and $d$ are highlighted in Table 3 .

\begin{tabular}{|c|c|c|c|c|c|c|c|c|c|c|c|c|c|c|c|c|}
\hline \multirow{2}{*}{$\frac{\dot{\Delta}}{E_{I}^{l}}$} & & \multicolumn{3}{|c|}{10} & \multicolumn{3}{|c|}{15} & \multicolumn{3}{|c|}{20} & \multicolumn{3}{|c|}{25} & \multicolumn{3}{|c|}{30} \\
\hline & & 300 & 600 & 900 & 300 & 600 & 900 & 300 & 600 & 900 & 300 & 600 & 900 & 300 & 600 & 900 \\
\hline & 20 & 1 & 2 & 3 & 4 & 5 & 6 & 7 & 8 & 9 & 10 & 11 & 12 & 13 & 14 & 15 \\
\hline$d$ & 10 & 16 & 17 & 18 & 19 & 20 & 21 & 22 & 23 & 24 & 25 & 26 & 27 & 28 & 29 & 30 \\
\hline & 5 & 31 & 32 & 33 & 34 & 35 & 36 & 37 & 38 & 39 & 40 & 41 & 42 & 43 & 44 & 45 \\
\hline
\end{tabular}

Table 3: Id of the instances with the associated characteristics.

They have been preprocessed in order to remove those coordinates $(i, j, k)$, such that each target can not be covered by any UAV located in $(i, j, k)$.

\section{$5.2 \quad$ Numerical Results}

The numerical results are collected in Table A.1 - A.4 of the appendix. The Tables report the value of the objective function (\#UAVs for $M_{1}$ and $M_{2}$, cost for $M_{c}$ ), the execution time in seconds (time) and the total energy consumption (energy), that is, the sum of the energy consumed by each activated UAV. It is worth observing that a time limit of 2 hours is imposed for $M_{1}, M_{2}$, and $M_{c}$. This case is highlighted under column time of Table A.1 of the Appendix with the entry TL.

The performance of the MIP-based heuristics is evaluated by considering the GAP calculated as $(f(M H)-f(M)) / f(M)$, where $f(M H)$ is the value of the solution determined by $M H$ and $f(M)$ is the value of objective function obtained by solving the models; the speed-up defined as the execution time of the models over that of $M H s$; and we also evaluate and compare the energy consumption for the solutions provided by the models and that related to the MIP-based heuristics (ENG in the following Tables).

Results for $M_{1}$ Table 4 shows the average performance of the model $M_{1}$ and the MIP-based heuristics. It is worth observing that we consider all the instances, also those for which model $M_{1}$ does not provide the optimal solution within the time limit.

The results underline that, on average, the MIP-based heuristics are more efficient than solving $M_{1}$. In particular, $M H s$ are 25.34 times faster than $M_{1}$. The gain in terms of efficiency is paid by the effectiveness. However, the upper bounds provided by $M H s$ are higher than the optimal solution of a factor of 0.25 (see column GAP).

Over all, we can conclude that the trade-off between speed-up and GAP is satisfactory. Indeed, we compare the performances of $M_{1}$ and $M H_{1}^{v}$ in terms of both \#UAVs and time for each instance (see Figure 2). It is worth observing that \#UAVs and time shown for the MIP-heuristics are those associated with the best \#UAVs among all the strategies $v=1, \ldots, 5$. 


\begin{tabular}{l|rrrrrr}
\cline { 2 - 7 } & \#UAVs & \multicolumn{1}{c}{ time } & energy & GAP & speed up & ENG \\
\hline$M_{1}$ & 21.18 & 5548.69 & 9570.58 & & & \\
$M H_{1}^{1}$ & 27.16 & 198.56 & 10780.32 & 0.28 & 27.94 & 1.13 \\
$M H_{1}^{2}$ & 25.73 & 186.22 & 10274.27 & 0.22 & 29.80 & 1.07 \\
$M H_{1}^{3}$ & 27.00 & 244.19 & 10655.38 & 0.27 & 22.72 & 1.11 \\
$M H_{1}^{4}$ & 27.09 & 132.73 & 10552.74 & 0.28 & 41.80 & 1.10 \\
$M H_{1}^{5}$ & 25.49 & 332.90 & 9997.82 & 0.20 & 16.67 & 1.04 \\
\hline AVG $M H$ & 26.49 & 218.92 & 10452.11 & 0.25 & 25.35 & 1.09 \\
\hline
\end{tabular}

Table 4: Average computational results obtained with $M_{1}$ and the associated MIP-based heuristics.

From Figure 2 it is evident the advantage of solving all the instances with the proposed $M H_{1}^{v}$. Indeed, the majority of the instances (35 out of 45) are not solved within the time limit by $M_{1}$. The gap between $M_{1}$ and $M H_{1}^{v}$ in term of computational cost is not comparable with the gap associated with the objective function.

Table 5 shows the average results over the 10 instances out of 45 solved within the time limit to optimality.

\begin{tabular}{l|rrrccc}
\cline { 2 - 7 } & \#UAVs & time & energy & GAP & speed up & ENG \\
\hline$M_{1}$ & 14.91 & 444.66 & 7749.91 & & & \\
$M H_{1}^{1}$ & 18.00 & 4.96 & 8210.27 & 0.21 & 89.63 & 1.06 \\
$M H_{1}^{2}$ & 17.45 & 4.80 & 8190.14 & 0.17 & 92.71 & 1.06 \\
$M H_{1}^{3}$ & 18.27 & 5.03 & 8306.82 & 0.23 & 88.37 & 1.07 \\
$M H_{1}^{4}$ & 17.64 & 3.96 & 7838.77 & 0.18 & 112.22 & 1.01 \\
$M H_{1}^{5}$ & 16.91 & 4.49 & 7677.95 & 0.13 & 98.97 & 0.99 \\
\hline AVG $M H$ & 17.65 & 4.65 & 8044.79 & 0.18 & 95.65 & 1.04 \\
\hline
\end{tabular}

Table 5: Average computational results over the instances solved before the time limit.

The speed-up increases, indeed, $M H s$ are, on average, 93.65 times faster than $M_{1}$. The GAP is improved to 0.18 , on average. Figure 3 highlights the difference in terms of effectiveness and efficiency between $M_{1}$ and $M H_{1}$ on the instances solved to optimality by $M_{1}$.

From Tables 4 and 5 we observe that $M H_{1}^{5}$ shows the best performance in terms of effectiveness. Indeed, the GAP is 0.20 and 0.13 when considering all the instances and only those for which $M_{1}$ provide the optimal solution (time less than time limit), respectively. The fastest version among $M H s$ is the $4^{t h}$. Indeed, $M H_{1}^{4}$ is faster than $M_{1}$ when considering the average results over all instances (Table 4) and those solved to optimality (Table 5), respectively. However, this version has the worst performance in terms of effectiveness, see Table 4.

Considering the overall energy consumption, the results obtained by $M_{1}$ are very similar to those of $M H s$. Indeed, the solution provided by $M_{1}$ allows to consume 1.09 and 1.04 times less energy than that required for the solution obtained by $M H s$, see column ENG of Tables 4 and 

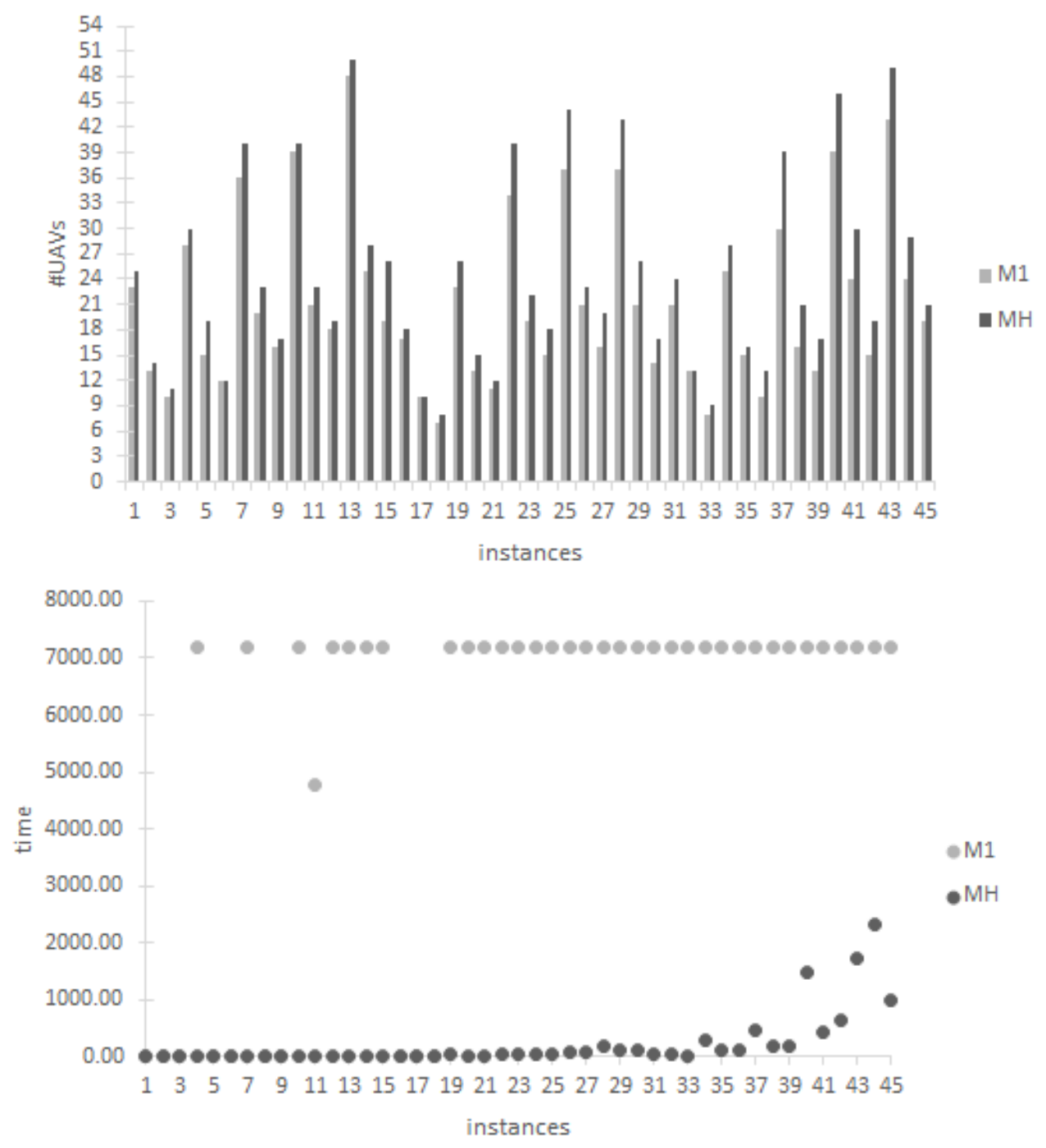

Figure 2: Values of objective function and computational cost for each instances.

\section{5 , respectively.}

Table 6 shows the average results over all instances varying the initial energy $E_{I}^{l}$.

As expected, the higher the initial energy, the lower the number of UAVs needed to monitor the targets. In addition, for both the models and the MIP-based heuristics, the execution time decreases when $E_{I}^{l}$ increases. An inverted trend is observed for the energy consumption (see column energy). This behaviour is justified by considering the fact that the UAVs are placed in a high altitude. The energy increases, but the available initial energy allows to use less UAVs and monitor a higher number of targets with the same UAV. 

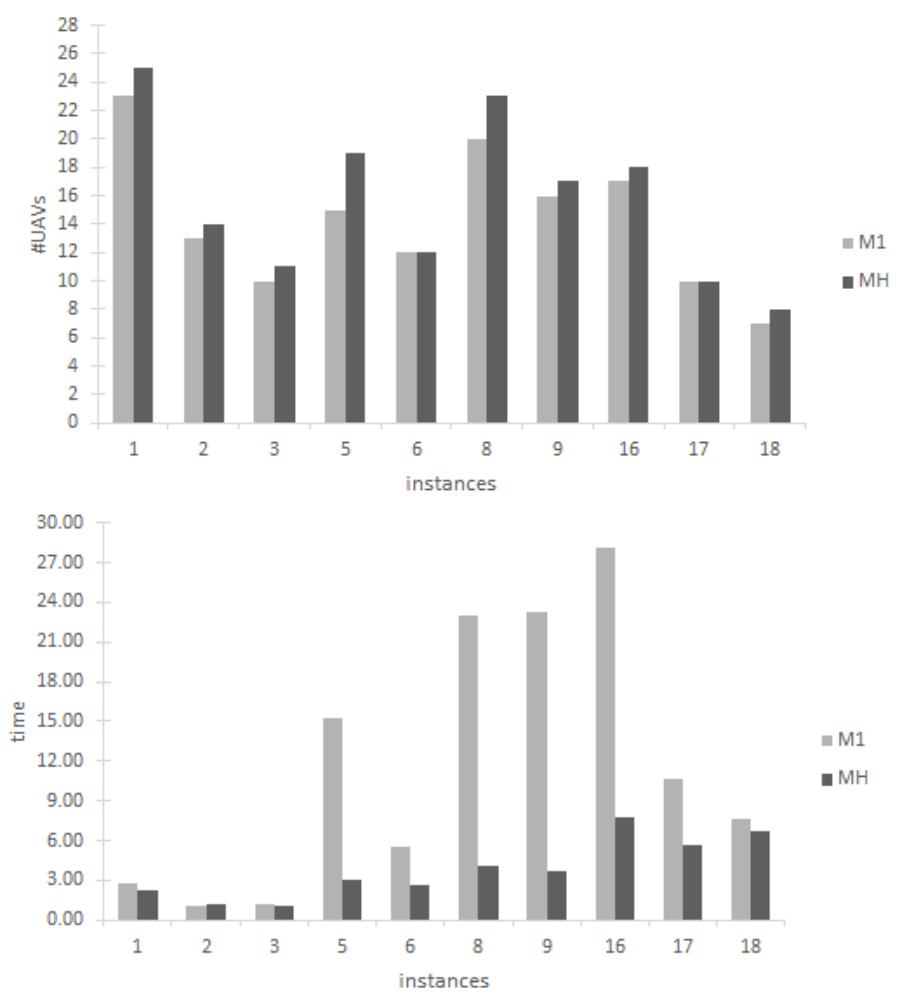

Figure 3: Values of objective function and computational cost for the instances solved to optimality by $M_{1}$.

\begin{tabular}{c|rccc|ccc}
\cline { 2 - 8 } \multicolumn{1}{c|}{$M_{1}$} & \multicolumn{3}{c}{$M H s$} \\
\hline$E_{I}^{l}$ & \#UAVs & time & energy & \#OPT & \#UAVs & time & energy \\
\hline 300 & 32.00 & 6242.06 & 9281.70 & 2 & 39.79 & 363.06 & 10049.49 \\
600 & 18.00 & 5121.51 & 9602.50 & 5 & 22.45 & 161.92 & 10475.66 \\
900 & 13.53 & 5282.52 & 9827.53 & 4 & 17.24 & 131.78 & 10831.17 \\
\hline
\end{tabular}

Table 6: Average computational results varying the initial energy.

Results for $M_{2}$ Table 7 shows the average performance of the model $M_{2}$ and the MIP-based heuristics.

On one hand, Table 7 shows that, on average, the $M H s$ are 57.11 times faster than $M_{2}$. On the other hand, the upper bounds provided by $M H s$ are higher of a factor of 0.25 than the optimal solution (see column GAP). Figure 4 shows the good performances of the proposed approach against the behaviour of $M_{1}$.

11 instances out of 45, are solved to optimality within the time limit. Table 8 shows the average results over these 11 instances and we can conclude that $M H s$ are, on average, 8.04 


\begin{tabular}{l|rrcccc}
\cline { 2 - 6 } & \#UAVs & \multicolumn{1}{c}{ time } & energy & GAP & speed-up & ENG \\
\hline$M_{2}$ & 17.78 & 5606.16 & 12803.38 & & & \\
$M H_{2}^{1}$ & 22.62 & 93.49 & 11110.27 & 0.27 & 59.97 & 1.15 \\
$M H_{2}^{2}$ & 22.13 & 100.68 & 11154.97 & 0.25 & 55.69 & 1.15 \\
$M H_{2}^{3}$ & 22.07 & 91.16 & 10933.06 & 0.24 & 61.50 & 1.17 \\
$M H_{2}^{4}$ & 22.22 & 105.49 & 11154.60 & 0.25 & 53.14 & 1.15 \\
$M H_{2}^{5}$ & 21.80 & 99.98 & 10765.19 & 0.23 & 56.07 & 1.19 \\
\hline AVG $M H$ & 22.17 & 98.16 & 11023.62 & 0.25 & 57.11 & 1.16 \\
\hline
\end{tabular}

Table 7: Average computational results obtained with $M_{2}$ and the associated MIP-based heuristics.

times faster than $M_{2}$ and the GAP is improved to 0.20 , on average.

\begin{tabular}{l|rrrrrr}
\cline { 2 - 7 } & \#UAVs & time & ENG & GAP & speed-up & ENG \\
\hline$M_{2}$ & 12.90 & 27.73 & 9569.25 & & & \\
$M H_{2}^{1}$ & 15.50 & 3.23 & 8040.80 & 0.20 & 8.58 & 1.59 \\
$M H_{2}^{2}$ & 15.80 & 3.39 & 8473.00 & 0.22 & 8.17 & 1.51 \\
$M H_{2}^{3}$ & 15.90 & 3.26 & 8366.60 & 0.23 & 8.51 & 1.53 \\
$M H_{2}^{4}$ & 16.10 & 3.47 & 8374.10 & 0.25 & 7.99 & 1.53 \\
$M H_{2}^{5}$ & 14.30 & 3.90 & 7538.85 & 0.11 & 7.12 & 1.70 \\
\hline AVG $M H$ & 15.52 & 3.45 & 8158.67 & 0.20 & 8.04 & 1.57 \\
\hline
\end{tabular}

Table 8: Average computational results over the instances solved before the time limit.

The results are satisfactory. Indeed, $\mathrm{MH}_{2}$ provides solutions close to the optimal ones is a limited amount of time. This aspect is highlighted in Figure 5.

Tables 7 and 8 show that $M H_{2}^{5}$ is the best in terms of effectiveness. Indeed, the GAP is 0.23 and 0.11 when considering all the instances and only those solved in the time limit, respectively. The fastest version among $M H s$ is the $3^{\text {rd }}$ for the former case (Table 7), whereas in the latter, $M H_{2}^{1}$ shows the best performance, see Table 8. Indeed, $M H_{2}^{3}$ and $M H_{2}^{1}$ are 64.49 and 8.57 times faster than solving $M_{2}$.

\begin{tabular}{c|rccc|ccc}
\cline { 2 - 8 } \multicolumn{1}{c|}{$M_{2}$} & \multicolumn{3}{c}{$M H s$} \\
\hline$E_{I}^{l}$ & \#UAVs & time & ENG & \#OPT & \#UAVs & time & ENG \\
\hline 300 & 21.80 & 6241.18 & 11467.47 & 2 & 27.81 & 125.61 & 10879.59 \\
600 & 17.40 & 5286.50 & 13115.83 & 5 & 21.71 & 92.57 & 10827.44 \\
900 & 14.13 & 5290.81 & 13826.83 & 4 & 16.99 & 76.29 & 11363.81 \\
\hline
\end{tabular}

Table 9: Average computational results varying the initial energy.

Considering the overall energy consumption, the results obtained by $M H s$ are always better than those of $M_{2}$. Indeed, the solution provided by $M H s$, on average, allows to consume 1.16 

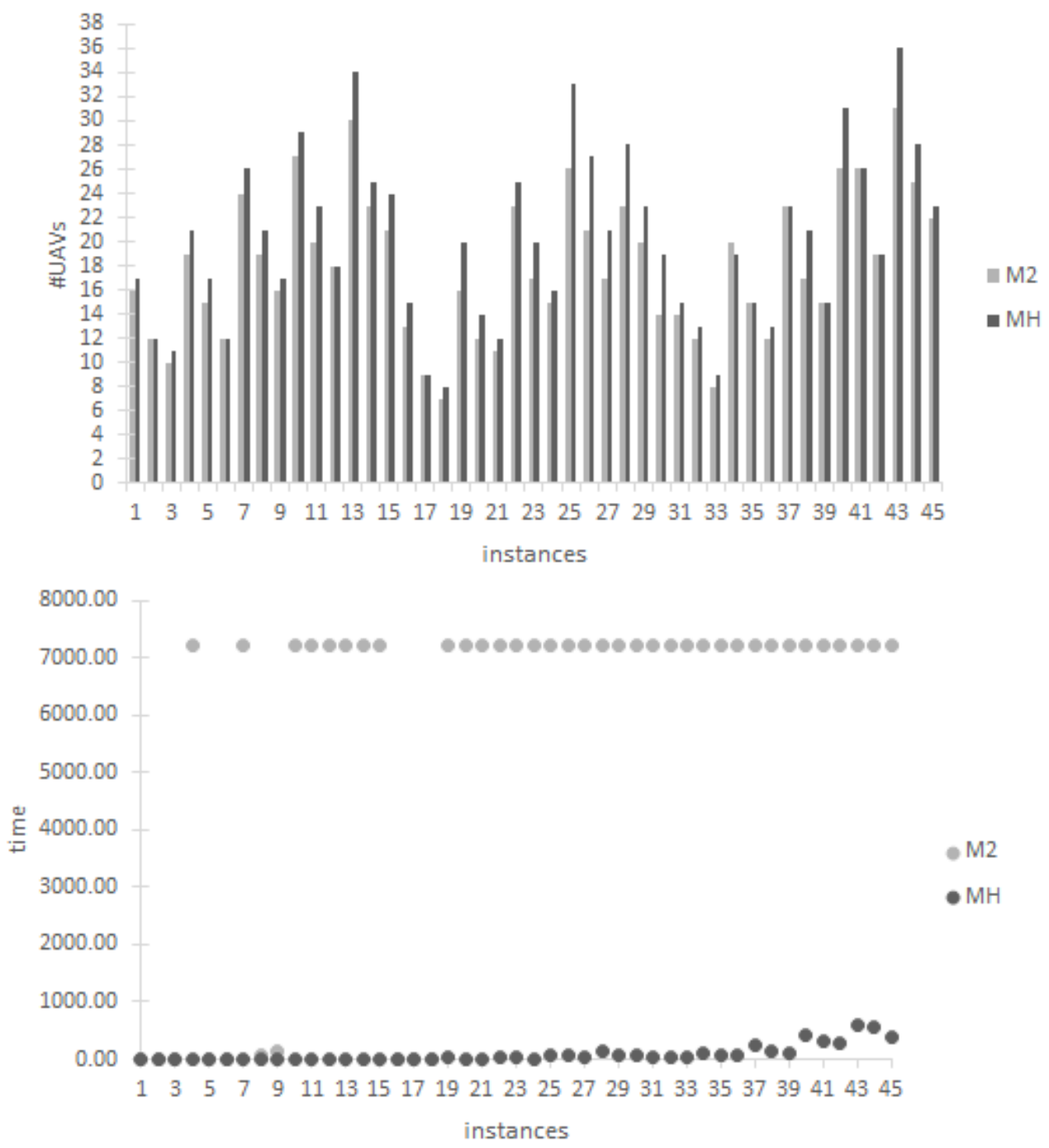

Figure 4: Values of objective function and computational cost for each instances.

and 1.57 times less energy than that required for the solution obtained by $M_{2}$, see column ENG of Table 7 and 8, respectively. See also column energy of Tables A.1 and A.3.

Table 9 shows the average results over all instances varying the initial energy $E_{I}^{l}$. The results are coherent with that obtained for model $M_{1}$.

Results for $M_{c}$ The MIP-based heuristics show a good performance considering model $M_{c}$. Table 10 reports the average results over all instances.

The GAP is drastically reduced comparing with the results obtained for both $M_{1}$ and $M_{2}$. 

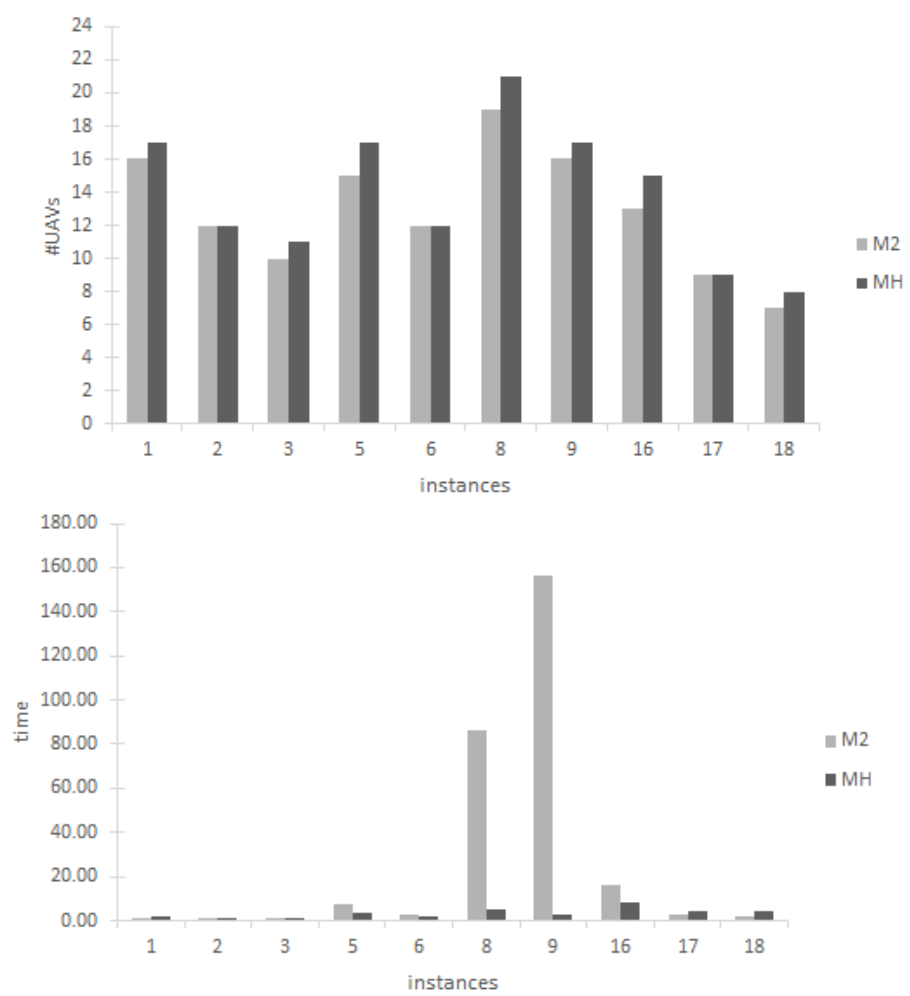

Figure 5: Values of objective function and computational cost for the instances solved to optimality by $M_{2}$.

\begin{tabular}{l|rrrrrr}
\cline { 2 - 6 } & \multicolumn{1}{c}{ cost } & \multicolumn{1}{c}{ time } & energy & GAP & speed-up & ENG \\
\hline$M_{c}$ & 9.13 & 4657.06 & 12958.52 & & & \\
$M H_{c}^{1}$ & 10.20 & 311.97 & 11527.53 & 0.12 & 14.93 & 1.12 \\
$M H_{c}^{2}$ & 10.09 & 248.72 & 11397.53 & 0.10 & 18.72 & 1.14 \\
$M H_{c}^{3}$ & 10.11 & 212.16 & 11562.47 & 0.11 & 21.95 & 1.12 \\
$M H_{c}^{4}$ & 10.09 & 262.65 & 11418.88 & 0.10 & 17.73 & 1.13 \\
$M H_{c}^{5}$ & 9.80 & 241.76 & 11283.23 & 0.07 & 19.26 & 1.15 \\
\hline AVG $M H$ & 10.06 & 255.45 & 11437.93 & 0.10 & 18.23 & 1.13 \\
\hline
\end{tabular}

Table 10: Average computational results obtained with $M_{c}$ and the associated MIP-based heuristics.

Indeed, on average, the upper bound is $10 \%$ higher than the objective value returned by the solver. In addition, $M H s$ are, on average, 18.23 times faster than the solver. Figure 6 shows the good performance of the MIP-based heuristic compared with $M_{c}$.

In particular, the best cost provided by $M H s$ is low or equal to the cost given by $M_{c}$ for 30 

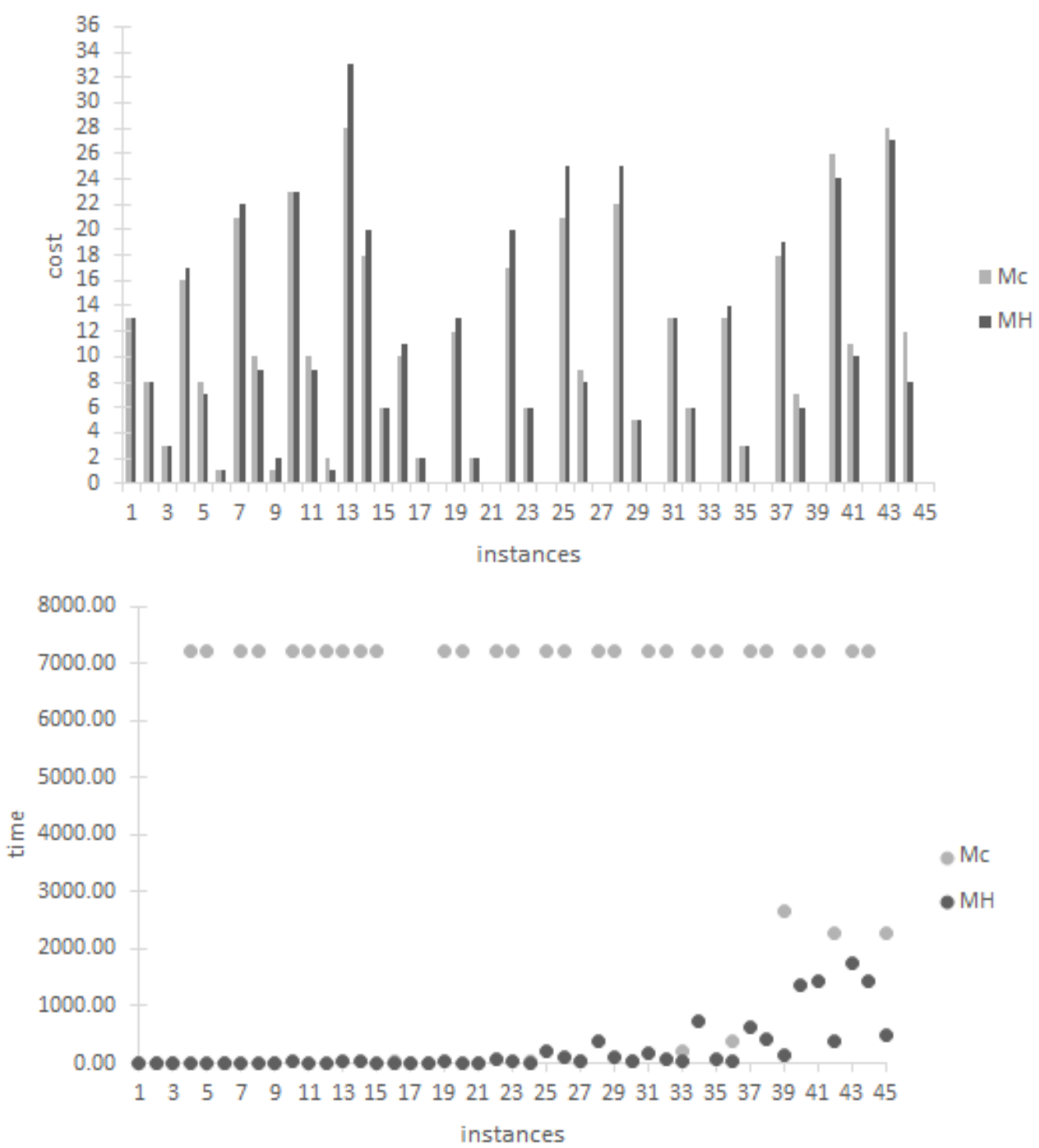

Figure 6: Values of objective function and computational cost for each instances.

instances out of 45 .

$M H_{c}^{5}$ is the most effective. Indeed, the GAP is about 0.07 . The best performance in terms of computational cost is achieved by $M H_{c}^{3}$. The third version of the MIP-based heuristic is 21.95 times faster than solving $M_{c}$.

17 out of 45 instances are solved to optimality. The average results over these instances are reported in Table 11.

Considering the results of Table 11, the speed-up of $M H s$ decreases. Indeed, on average, solving $M_{c}$ is 5.81 times slower than $M H s$. The GAP increases to $17 \%$. 


\begin{tabular}{l|crcccc}
\cline { 2 - 7 } & cost & time & ENG & GAP & speed-up & ENG \\
\hline$M_{c}$ & 2.24 & 468.68 & 12770.79 & & & \\
$M H_{c}^{1}$ & 2.71 & 78.04 & 10801.88 & 0.21 & 6.01 & 1.18 \\
$M H_{c}^{2}$ & 2.53 & 81.28 & 10702.21 & 0.13 & 5.77 & 1.19 \\
$M H_{c}^{3}$ & 2.59 & 78.81 & 10819.82 & 0.16 & 5.95 & 1.18 \\
$M H_{c}^{4}$ & 2.76 & 85.28 & 10848.56 & 0.24 & 5.50 & 1.18 \\
$M H_{c}^{5}$ & 2.47 & 79.64 & 10639.06 & 0.11 & 5.88 & 1.20 \\
\hline AVG $M H$ & 2.61 & 80.61 & 10762.31 & 0.17 & 5.81 & 1.19 \\
\hline
\end{tabular}

Table 11: Average computational results over the instances solved before the time limit.

In the majority of the case, i.e. 15 out 17, the upper bound obtained with $M H s$ is equal to the optimal cost (see Figure 7 ). This results is achieved within a very limit computational cost.
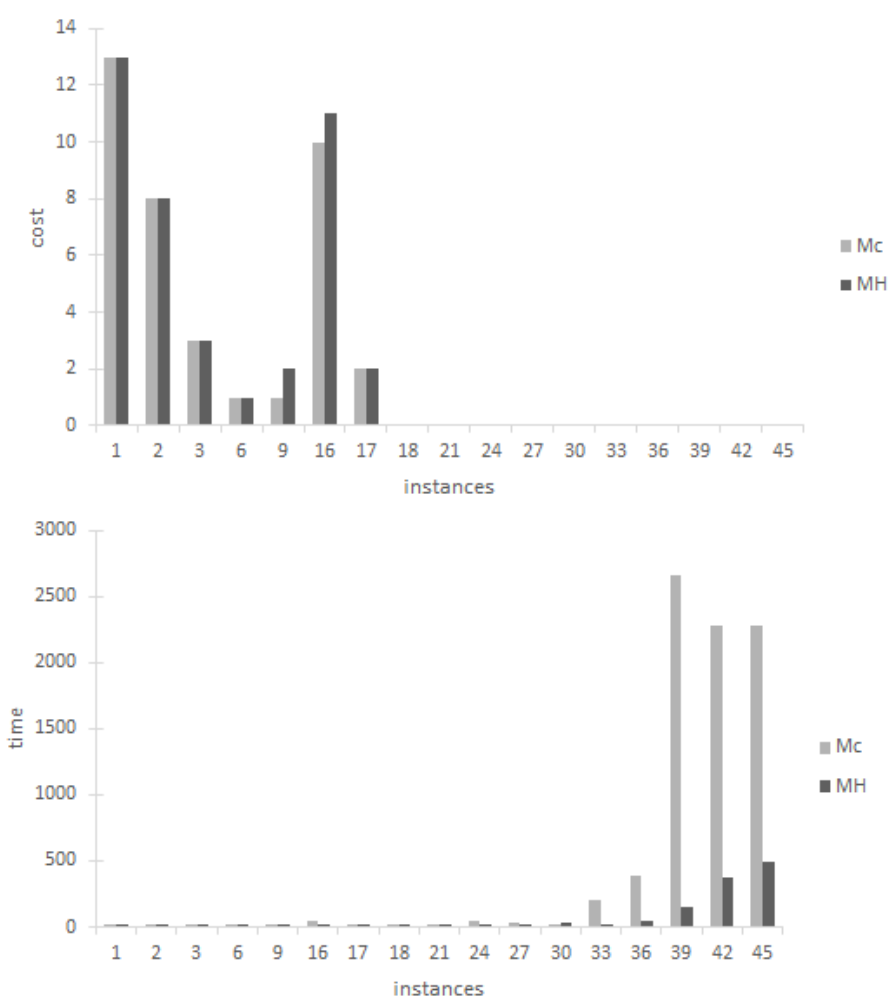

Figure 7: Values of objective function and computational cost for the instances solved to optimality by $M_{2}$.

Table 12 shows that for initial energy equal to 600, the performance of the $M H s$ are the best. Indeed, the optimality gap is 0.01 . In addition, the $M H s$ are very efficient being, on average, $14.58,25.26$, and 16.31 times faster than $M_{c}$, for $E_{I}^{l}$ equal to 300,600 , and 900 , respectively. 


\begin{tabular}{c|rccc|ccc}
\cline { 2 - 8 } \multicolumn{1}{|c|}{} & \multicolumn{4}{|c|}{$M_{2}$} & \multicolumn{3}{c}{$M H s$} \\
\hline$E_{I}^{l}$ & \multicolumn{1}{|c}{ cost } & time & energy & \#OPT & cost & time & energy \\
\hline 300 & 18.73 & 6242.91 & 10812.70 & 2 & 21.28 & 428.05 & 10508.80 \\
600 & 7.80 & 6240.59 & 12738.63 & 2 & 7.89 & 247.08 & 11166.00 \\
900 & 0.87 & 1487.66 & 15324.23 & 13 & 1.00 & 91.22 & 12638.99 \\
\hline
\end{tabular}

Table 12: Average computational results varying the initial energy.

Considering the overall energy consumption, the $M H s$ show the best performance. Indeed, the allocation of the UAVs given by the MIP-based heuristics allows the system to consume, on average, 1.14 times lower energy than that required by the system for the solutions obtained by solving $M_{c}$ (see Table 10). The gap in terms of energy consumption increases considering the instances solved to optimality. Indeed, the energy consumed with the deployment ginen by $M H s$ is 1.18 times less than that consumed by the UAVs in the solution given by $M_{c}$ (see Table $11)$.

\subsection{Number of UAVs versus Energy Consumption}

During the computational phase, we have observed that minimizing the number of UAVs is not equivalent to the problem in which the overall energy consumption of the system has to be minimized. Indeed, for some instances, model $M_{1}$ provides a solution for which the number of UAVs activated is lower than that required by the solution obtained when the total energy consumption is minimized.

This trend is shown in Table 13, where the average number of UAVs and the average energy consumption is reported for model $M_{1}$ and model (2) - (7), (9) with the minimization of $\sum_{l \in L} E^{l}$, with $E^{l}$ defined in (26), referred to as $M_{1}^{E}$.

\begin{tabular}{c|rrr|rrr}
\cline { 2 - 7 } \multicolumn{1}{c|}{} & \multicolumn{3}{|c|}{$M_{1}^{E}$} & \multicolumn{3}{c}{$M_{1}$} \\
\hline$d$ & \#UAVs & energy & time & \#UAVs & energy & time \\
\hline 20 & 23.27 & 9051.40 & 707.12 & 22.87 & 10136.17 & 867.88 \\
10 & 20.13 & 7617.00 & 926.39 & 19.67 & 8606.53 & 1272.12 \\
5 & 22.33 & 8145.79 & 1605.53 & 22.20 & 10579.33 & 1678.71 \\
\hline
\end{tabular}

Table 13: Average results of model $M_{1}$ with the minimization of the energy consumption and the minimization of the number of UAVs.

The first observation is that model $M_{1}^{E}$ is slightly easier to solve than $M_{1}$. Indeed, solving $M_{1}^{E}$ requires less computational effort than solving $M_{1}$ (see column time of Table 13).

Investigating the conflicting nature of the two objective functions is out of the scope of this work. However, we believe that this aspect is worth to be investigated. In particular, it is interesting to study the bi-objective problem and define well-tailored approaches in order to give to the decision maker the possibility of choosing the most satisfactory solution among the efficient ones. Possible algorithmic approaches could be defined by considering scalarizing 
techniques, such as the reference point method [7,25], the exploration of the criteria space with the $\epsilon$-constraint algorithm $[2,8]$ and the so-called hull approach for determining the supported non-dominated solutions [13].

\section{Conclusions}

In this paper, we have considered the problem of covering a certain number of mobile targets by using flying drones (UAVs). Each target must be observed at any time and any place. In addition, each UAV has a limited amount of initial energy. The energy consumption is related to the altitude in which the UAV is located. The higher the altitude, the higher the energy consumption. A time window of observation is associated with each target. The objective is to monitor all targets minimizing the number of UAVs. We address the problem under optimization perspective, thus, mathematical formulations are given under specific assumptions.

We have considered two cases. In the former, when an UAV runs out of battery, it is replaced by an identical one; in the latter, we consider a set of available UAVs, with different initial energy, defining different types of flying drones. Thus, when an UAV have to be substituted, the optimization process individuates the type of UAV that has to replace the previous one. We have also considered a version in which the total cost for activating different types of UAVs is minimized.

The three problems are modeled as mixed integer non-linear programs. Several valid cuts have been introduced and the models have been linearized. Due to the difficulty in solving to optimality the problems, heuristics based on the resolution of restricted mixed integer programs have been defined.

The linearized models and the heuristic procedures have been tested on meaningful instances generated by ourselves. The computational results have underlined the difficulty of the problems and for only $23 \%$ of the instances the solver has been able to provide the optimal solution in 2 hours. Better results have been obtained for the minimization of the activation cost. In this case, the $38 \%$ of instances have been solved to optimality by the solver. The heuristics have shown very promising performance exhibiting a reasonable trade-off between quality of the solution and computational effort.

In addition, we have observed that the minimization of the number of UAVs and the minimization of the total energy consumption are objective in conflict. Thus, the bi-objective version of the problem is worth to be investigated. 


\section{Appendix}

\begin{tabular}{|c|c|c|c|c|c|c|c|c|c|c|c|}
\hline \multirow[b]{2}{*}{$|\dot{\Delta}|$} & \multirow[b]{2}{*}{$d$} & \multirow[b]{2}{*}{$E_{I}^{l}$} & \multicolumn{3}{|c|}{$M_{1}$} & \multicolumn{3}{|c|}{$M_{2}$} & \multicolumn{3}{|c|}{$M_{c}$} \\
\hline & & & \#UAVs & time & energy & \#UAVs & time & energy & cost & time & energy \\
\hline 10 & 20 & 300 & 23 & 2.71 & 6577.50 & 16 & 1.45 & 7602.50 & 13 & 2.93 & 7015.00 \\
\hline 10 & 20 & 600 & 13 & 1.08 & 6482.50 & 12 & 0.94 & 9315.00 & 8 & 2.40 & 8232.50 \\
\hline 10 & 20 & 900 & 10 & 1.26 & 6162.50 & 10 & 0.66 & 7430.00 & 3 & 0.75 & 9335.00 \\
\hline 15 & 20 & 300 & 28 & $\mathrm{TL}$ & 7905.00 & 19 & $\mathrm{TL}$ & 9120.00 & 16 & TL & 8802.50 \\
\hline 15 & 20 & 600 & 15 & 15.24 & 8045.00 & 15 & 7.52 & 8977.50 & 8 & TL & 10335.00 \\
\hline 15 & 20 & 900 & 12 & 5.48 & 8730.00 & 12 & 2.76 & 10877.50 & 1 & 1.73 & 11167.50 \\
\hline 20 & 20 & 300 & 36 & $\mathrm{TL}$ & 10330.50 & 24 & TL & 11550.00 & 21 & TL & 12095.00 \\
\hline 20 & 20 & 600 & 20 & 23.03 & 10823.00 & 19 & 86.41 & 14382.50 & 10 & TL & 13201.50 \\
\hline 20 & 20 & 900 & 16 & 23.32 & 11555.00 & 16 & 156.50 & 17455.00 & 1 & 3.34 & 15700.00 \\
\hline 25 & 20 & 300 & 39 & TL & 11325.00 & 27 & TL & 12089.50 & 23 & TL & 14189.50 \\
\hline 25 & 20 & 600 & 21 & 4772.71 & 11696.00 & 20 & $\mathrm{TL}$ & 13427.50 & 10 & TL & 15115.50 \\
\hline 25 & 20 & 900 & 18 & $\mathrm{TL}$ & 11975.50 & 18 & $\mathrm{TL}$ & 16425.00 & 2 & TL & 15425.00 \\
\hline 30 & 20 & 300 & 48 & $\mathrm{TL}$ & 13250.00 & 30 & $\mathrm{TL}$ & 15565.00 & 28 & TL & 17652.50 \\
\hline 30 & 20 & 600 & 25 & $\mathrm{TL}$ & 13532.50 & 23 & $\mathrm{TL}$ & 22432.50 & 18 & $\mathrm{TL}$ & 20175.00 \\
\hline 30 & 20 & 900 & 19 & $\mathrm{TL}$ & 13652.50 & 21 & $\mathrm{TL}$ & 21665.00 & 6 & $\mathrm{TL}$ & 25020.00 \\
\hline 10 & 10 & 300 & 17 & 28.11 & 5005.00 & 13 & 16.22 & 7245.00 & 10 & 40.78 & 5640.00 \\
\hline 10 & 10 & 600 & 10 & 10.61 & 5140.00 & 9 & $\begin{array}{r}2.59 \\
\end{array}$ & 4807.50 & 2 & 6.44 & 6797.50 \\
\hline 10 & 10 & 900 & 7 & 7.68 & 5032.50 & 7 & 2.28 & 7600.00 & 0 & 3.88 & \\
\hline 15 & 10 & 300 & 23 & TL & 6555.00 & 16 & $\mathrm{TL}$ & 9605.00 & 12 & TL & 7282.00 \\
\hline 15 & 10 & 600 & 13 & $\mathrm{TL}$ & 6467.50 & 12 & $\mathrm{TL}$ & 9310.00 & 2 & TL & 8881.50 \\
\hline 15 & 10 & 900 & 11 & $\mathrm{TL}$ & 6790.00 & 11 & $\mathrm{TL}$ & 9885.00 & 0 & 6.83 & 11110.00 \\
\hline 20 & 10 & 300 & 34 & $\mathrm{TL}$ & 9602.50 & 23 & $\mathrm{TL}$ & 11317.50 & 17 & $\mathrm{TL}$ & 11795.50 \\
\hline 20 & 10 & 600 & 19 & TL & 8969.00 & 17 & TL & 11702.50 & 6 & TL & 13585.50 \\
\hline 20 & 10 & 900 & 15 & TL & 9471.50 & 15 & $\mathrm{TL}$ & 12907.50 & 0 & 49.78 & 15442.50 \\
\hline 25 & 10 & 300 & 37 & $\mathrm{TL}$ & 10902.00 & 26 & $\mathrm{TL}$ & 13100.00 & 21 & TL & 11477.00 \\
\hline 25 & 10 & 600 & 21 & $\mathrm{TL}$ & 10896.50 & 21 & $\mathrm{TL}$ & 15120.00 & 9 & $\mathrm{TL}$ & 15592.50 \\
\hline 25 & 10 & 900 & 16 & $\mathrm{TL}$ & 11061.50 & 17 & $\mathrm{TL}$ & 14400.00 & 0 & 26.68 & 19930.00 \\
\hline 30 & 10 & 300 & 37 & $\mathrm{TL}$ & 11005.00 & 23 & $\mathrm{TL}$ & 12875.00 & 22 & TL & 11785.00 \\
\hline 30 & 10 & 600 & 21 & $\mathrm{TL}$ & 11427.50 & 20 & $\mathrm{TL}$ & 15875.00 & 5 & $\mathrm{TL}$ & 17420.00 \\
\hline 30 & 10 & 900 & 14 & $\mathrm{TL}$ & 10772.50 & 14 & $\mathrm{TL}$ & 12867.50 & 0 & 22.23 & 19805.00 \\
\hline 10 & 5 & 300 & 21 & $\mathrm{TL}$ & 6207.50 & 14 & $\mathrm{TL}$ & 7050.00 & 13 & $\mathrm{TL}$ & 7252.50 \\
\hline 10 & 5 & 600 & 13 & $\mathrm{TL}$ & 6387.50 & 12 & $\mathrm{TL}$ & 7307.50 & 6 & TL & 7097.50 \\
\hline 10 & 5 & 900 & 8 & $\mathrm{TL}$ & 6490.00 & 8 & $\mathrm{TL}$ & 8137.50 & 0 & 199.5 & 8375.00 \\
\hline 15 & 5 & 300 & 25 & $\mathrm{TL}$ & 7500.00 & 20 & $\mathrm{TL}$ & 10972.50 & 13 & TL & 8339.00 \\
\hline 15 & 5 & 600 & 15 & $\mathrm{TL}$ & 8597.50 & 15 & $\mathrm{TL}$ & 11150.00 & 3 & TL & 9430.00 \\
\hline 15 & 5 & 900 & 10 & $\mathrm{TL}$ & 8060.50 & 12 & $\mathrm{TL}$ & 8692.50 & 0 & 391.38 & 12742.50 \\
\hline 20 & 5 & 300 & 30 & TL & 8997.50 & 23 & $\mathrm{TL}$ & 13180.00 & 18 & TL & 10285.00 \\
\hline 20 & 5 & 600 & 16 & TL & 9257.50 & 17 & $\mathrm{TL}$ & 12895.00 & 7 & TL & 12964.50 \\
\hline 20 & 5 & 900 & 13 & $\mathrm{TL}$ & 10930.00 & 15 & $\mathrm{TL}$ & 15497.50 & 0 & 2653.98 & 17000.00 \\
\hline 25 & 5 & 300 & 39 & $\mathrm{TL}$ & 11690.50 & 26 & $\mathrm{TL}$ & 14077.50 & 26 & TL & 13967.50 \\
\hline 25 & 5 & 600 & 24 & $\mathrm{TL}$ & 13156.50 & 26 & $\mathrm{TL}$ & 16480.00 & 11 & TL & 15910.00 \\
\hline 25 & 5 & 900 & 15 & $\mathrm{TL}$ & 12986.50 & 19 & $\mathrm{TL}$ & 16365.00 & 0 & 2271.48 & 20250.00 \\
\hline 30 & 5 & 300 & 43 & $\mathrm{TL}$ & 12372.50 & 31 & TL & 17140.00 & 28 & TL & 14612.50 \\
\hline 30 & 5 & 600 & 24 & TL & 13159.00 & 25 & TL & 20675.00 & 12 & TL & 16341.00 \\
\hline 30 & 5 & 900 & 19 & $\mathrm{TL}$ & 13742.50 & 22 & $\mathrm{TL}$ & 21267.50 & 0 & 2283.37 & 21011.00 \\
\hline
\end{tabular}

Table A.1: Computational results obtained when solving $M_{1}, M_{2}$, and $M_{c}$. 


\begin{tabular}{|c|c|c|c|c|c|c|c|c|c|c|c|c|c|c|c|c|c|}
\hline & & & & $M H_{1}^{1}$ & & & $M H_{1}^{2}$ & & & $M H_{1}^{3}$ & & & $M H_{1}^{4}$ & & & $M H_{1}^{5}$ & \\
\hline$|\dot{\Delta}|$ & $d$ & $E_{I}^{l}$ & \#UAVs & time & energy & \#UAVs & time & energy & \#UAVs & time & energy & \#UAVs & time & energy & \#UAVs & time & energy \\
\hline 10 & 20 & 300 & & 2.70 & 7410.00 & & 1.62 & 7675.00 & 31 & 3.01 & 7907.50 & 31 & 1.67 & 7710.00 & 25 & 2.20 & 6502.50 \\
\hline 10 & 20 & 600 & 15 & 1.26 & 7412.50 & 15 & 1.67 & 7685.00 & 14 & 0.98 & 7180.00 & 14 & 1.58 & 6907.50 & 14 & 1.26 & 6507.50 \\
\hline 10 & 20 & 900 & 12 & 0.97 & 7140.00 & 11 & 0.97 & 6632.50 & 14 & 0.97 & 7847.50 & 11 & 0.95 & 6235.00 & 11 & 1.01 & 6590.00 \\
\hline 15 & 20 & 300 & 30 & 3.65 & 7660.00 & 33 & 3.54 & 8295.00 & 34 & 3.67 & 8715.00 & 32 & 3.59 & 8012.50 & 33 & 3.26 & 8202.50 \\
\hline 15 & 20 & 600 & 19 & 3.56 & 8290.00 & 20 & 3.04 & 8762.50 & 20 & 3.62 & 8880.00 & 19 & 3.09 & 8475.00 & 20 & 3.18 & 8955.00 \\
\hline 15 & 20 & 900 & 13 & 3.18 & 8730.00 & 14 & 3.20 & 9732.50 & 13 & 3.00 & 8732.50 & 12 & 2.62 & 8295.00 & 13 & 2.28 & 8380.00 \\
\hline 20 & 20 & 300 & 40 & 5.30 & 10648.00 & 40 & 6.15 & 10608.00 & 40 & 4.95 & 10663.00 & 42 & 5.32 & 10843.00 & 40 & 4.43 & 10135.50 \\
\hline 20 & 20 & 600 & 23 & 4.93 & 10713.00 & 23 & 6.05 & 11048.00 & 23 & 4.70 & 10948.00 & 25 & 5.21 & 11443.00 & 23 & 4.12 & 11053.00 \\
\hline 20 & 20 & 900 & 17 & 4.29 & 11573.00 & 18 & 4.34 & 11573.00 & 17 & 4.09 & 11328.00 & 17 & 3.70 & 10593.00 & 18 & 4.45 & 11453.00 \\
\hline 25 & 20 & 300 & 45 & 13.43 & 11559.00 & 45 & 14.31 & 11400.50 & 40 & 12.78 & 10626.50 & 48 & 11.73 & 12058.00 & 46 & 11.34 & 11589.00 \\
\hline 25 & 20 & 600 & 28 & 11.76 & 12494.50 & 24 & 12.36 & 11080.50 & 26 & 12.90 & 12194.00 & 23 & 10.53 & 10183.00 & 26 & 10.72 & 11424.00 \\
\hline 25 & 20 & 900 & 23 & 11.23 & 13584.00 & 21 & 11.20 & 12183.00 & 20 & 11.70 & 12374.00 & 20 & 10.11 & 12645.50 & 19 & 9.73 & 11479.00 \\
\hline 30 & 20 & 300 & 62 & 17.16 & 16360.00 & 50 & 19.97 & 13470.00 & 57 & 15.79 & 14912.50 & 59 & 16.15 & 15615.00 & 55 & 15.41 & 15260.00 \\
\hline 30 & 20 & 600 & 36 & 17.52 & 16772.50 & 28 & 17.80 & 13470.00 & 32 & 14.77 & 15052.50 & 33 & 16.19 & 15535.00 & 32 & 13.56 & 15837.50 \\
\hline 30 & 20 & 900 & 27 & 16.58 & 18247.50 & 27 & 19.05 & 16190.00 & 26 & 14.70 & 17222.50 & 26 & 13.59 & 17367.50 & 26 & 14.27 & 16655.00 \\
\hline 10 & 10 & 300 & 21 & 8.10 & 5275.00 & 19 & 7.19 & 5160.00 & 21 & 8.95 & 5387.50 & 20 & 5.35 & 5415.00 & 18 & 7.74 & 4430.00 \\
\hline 10 & 10 & 600 & 12 & 6.83 & 5487.50 & 10 & 6.69 & 4947.50 & 12 & 6.02 & 5485.00 & 12 & 5.21 & 5485.00 & 10 & 5.71 & 4430.00 \\
\hline 10 & 10 & 900 & 10 & 6.99 & 5787.50 & 10 & 5.63 & 5795.00 & 10 & 7.11 & 5485.00 & 10 & 3.68 & 5485.00 & 8 & 6.75 & 4732.50 \\
\hline 15 & 10 & 300 & 27 & 31.42 & 6634.00 & 28 & 32.87 & 7001.50 & 26 & 30.28 & 6311.50 & 30 & $\begin{array}{r}5.00 \\
27.11\end{array}$ & 7309.00 & 27 & 26.80 & 6757.00 \\
\hline 15 & 10 & 600 & 16 & 27.19 & 7004.00 & 16 & 21.72 & 6884.00 & 15 & 24.18 & 6684.00 & 16 & 19.89 & 7184.50 & 15 & 18.21 & 6602.50 \\
\hline 15 & 10 & $\begin{array}{l}000 \\
900\end{array}$ & 14 & $\begin{array}{l}31.59 \\
31.59\end{array}$ & 7641.50 & 12 & 26.04 & 7014.50 & 14 & 28.80 & 7641.50 & 14 & $\begin{array}{l}19.09 \\
17.89\end{array}$ & $\begin{array}{l}104.00 \\
7492.00\end{array}$ & 13 & $\begin{array}{l}10.21 \\
21.53\end{array}$ & 7475.00 \\
\hline 20 & 10 & 300 & 40 & 42.04 & 10543.50 & 42 & 43.06 & 11031.00 & 41 & 43.66 & 10156.00 & 43 & 40.67 & 10881.00 & 41 & 34.24 & 10461.00 \\
\hline 20 & 10 & 600 & 24 & 21.18 & 12171.00 & 25 & 34.99 & 11426.00 & 25 & 25.43 & 11278.50 & 22 & 41.11 & 10349.00 & 24 & 31.86 & 10876.00 \\
\hline 20 & 10 & 900 & 20 & 48.17 & 12286.00 & 20 & 36.72 & 12568.50 & 18 & 44.32 & 10596.00 & 19 & 29.37 & 11944.00 & 20 & 32.73 & 11829.00 \\
\hline 25 & 10 & 300 & 48 & 100.36 & 12013.00 & 51 & 109.50 & 13187.00 & 53 & 102.68 & 13358.00 & 50 & 94.63 & 12923.00 & 44 & 59.61 & 11433.00 \\
\hline 25 & 10 & 600 & 31 & 86.46 & 13637.00 & 29 & 84.37 & 13874.50 & 30 & 82.40 & 13659.50 & 30 & 92.62 & 12825.50 & 23 & 68.30 & 10497.50 \\
\hline 25 & 10 & 900 & 21 & 80.64 & 13005.50 & 20 & 83.12 & 13050.50 & 22 & 104.26 & 13448.00 & 21 & 45.49 & 13140.50 & 20 & 91.31 & 12847.50 \\
\hline 30 & 10 & 300 & 56 & 383.89 & 14208.50 & 43 & 203.63 & 11250.00 & 55 & 170.98 & 13341.00 & 56 & 136.52 & 13651.00 & 49 & 208.43 & 12123.50 \\
\hline 30 & 10 & 600 & 31 & 121.23 & 14036.00 & 26 & 112.77 & 12421.00 & 29 & 125.41 & 13983.50 & 29 & 123.65 & 13501.00 & 27 & 92.76 & 12881.00 \\
\hline 30 & 10 & 900 & 23 & 157.31 & 13388.50 & 17 & 118.84 & 12110.00 & 23 & 142.12 & 13533.50 & 21 & 146.36 & 12743.50 & 22 & 161.04 & 13116.00 \\
\hline 10 & 5 & 300 & 25 & 50.65 & 6374.50 & 24 & $\begin{array}{r}110.04 \\
43.66\end{array}$ & 6058.50 & 25 & $\begin{array}{r}142.12 \\
55.51\end{array}$ & 6238.50 & 25 & $\begin{array}{r}140.00 \\
40.34\end{array}$ & 6053.50 & 24 & $\begin{array}{r}101.04 \\
97.56\end{array}$ & 5913.50 \\
\hline 10 & $\begin{array}{l}5 \\
5\end{array}$ & 600 & 13 & 56.30 & 5896.00 & 13 & $\begin{array}{l}5.00 \\
50.00\end{array}$ & 6139.50 & 13 & $\begin{array}{l}37.01 \\
47.28\end{array}$ & 6819.50 & 16 & $\begin{array}{l}4.04 \\
44.91\end{array}$ & 7668.50 & $\begin{array}{l}24 \\
13\end{array}$ & 54.94 & 6154.50 \\
\hline 10 & $\begin{array}{l}5 \\
5\end{array}$ & $\begin{array}{l}600 \\
900\end{array}$ & $\begin{array}{r}13 \\
9\end{array}$ & $\begin{array}{l}56.30 \\
32.25\end{array}$ & $\begin{array}{l}5896.00 \\
6674.50\end{array}$ & $\begin{array}{r}13 \\
9\end{array}$ & $\begin{array}{l}52.00 \\
32.78\end{array}$ & $\begin{array}{l}6139.50 \\
6123.50\end{array}$ & $\begin{array}{r}13 \\
9\end{array}$ & $\begin{array}{l}4.28 \\
32.84\end{array}$ & $\begin{array}{l}6819.50 \\
6146.00\end{array}$ & $\begin{array}{r}10 \\
9\end{array}$ & $\begin{array}{l}44.91 \\
24.34\end{array}$ & 6053.50 & $\begin{array}{r}13 \\
9\end{array}$ & $\begin{array}{l}54.94 \\
33.56\end{array}$ & $\begin{array}{l}6154.50 \\
5913.50\end{array}$ \\
\hline 15 & 5 & 300 & 28 & 277.09 & 6853.00 & 29 & 397.18 & 7036.50 & 29 & 462.03 & 7169.00 & 30 & 138.70 & 7445.50 & 30 & 782.24 & 7349.00 \\
\hline 15 & 5 & 600 & 17 & 159.04 & 8279.00 & 17 & 120.03 & 8511.50 & 18 & 162.91 & 8159.00 & 16 & 126.39 & 7441.50 & 17 & 335.54 & 8159.00 \\
\hline 15 & 5 & 900 & 14 & 114.55 & 8456.50 & 14 & 141.76 & 8353.50 & 14 & 115.41 & 8834.00 & 13 & 106.52 & 8385.50 & 14 & 159.99 & 8414.50 \\
\hline 20 & 5 & 300 & 45 & 251.74 & 10405.00 & 42 & 216.64 & 9873.00 & 39 & 465.04 & 9604.50 & 43 & 209.65 & 10281.50 & 40 & 269.51 & 9422.00 \\
\hline 20 & 5 & 600 & 24 & 254.92 & 10386.00 & 22 & 235.89 & 10394.50 & 25 & 283.55 & 11092.50 & 21 & 209.76 & 10221.50 & 21 & 174.18 & 9925.50 \\
\hline 20 & 5 & 900 & 17 & 308.91 & 11213.50 & 18 & 192.27 & 10588.00 & 18 & 208.99 & 11549.00 & 17 & 221.30 & 10379.00 & 17 & 182.88 & 9504.00 \\
\hline 25 & 5 & 300 & 49 & 543.01 & 11802.00 & 53 & 1024.18 & 12700.50 & 56 & 693.81 & 13480.00 & 56 & 1074.96 & 13139.50 & 46 & 1483.37 & 11111.50 \\
\hline 25 & 5 & 600 & 30 & 530.61 & 13812.00 & 30 & 694.27 & 14495.00 & 30 & 738.01 & 13130.50 & 30 & 414.90 & 13215.00 & 30 & 514.09 & 13193.50 \\
\hline 25 & 5 & 900 & 21 & 461.39 & 13797.50 & 21 & 614.83 & 13160.00 & 21 & 598.01 & 13876.00 & 20 & 367.44 & 13628.50 & 19 & 645.22 & 12705.50 \\
\hline 30 & 5 & 300 & 61 & 3109.05 & 15438.50 & 49 & 1715.03 & 12301.50 & 60 & 4665.82 & 15185.50 & 60 & 726.11 & 15158.50 & 53 & 6274.03 & 13237.50 \\
\hline 30 & 5 & 600 & 31 & 824.42 & 15871.50 & 31 & 848.41 & 15647.50 & 30 & 731.83 & 15074.00 & 33 & 741.18 & 16579.00 & 29 & 2318.32 & 13494.00 \\
\hline 30 & 5 & 900 & 26 & 690.43 & 18142.50 & 21 & 1000.59 & 13432.50 & 27 & 669,40 & 18202,00 & 25 & 590,85 & 16976,00 & 23 & 686,72 & 14889,50 \\
\hline
\end{tabular}

Table A.2: Computational results obtained with the MIP-based heuristics when solving model $M_{1}$. 


\begin{tabular}{|c|c|c|c|c|c|c|c|c|c|c|c|c|c|c|c|c|c|}
\hline & & & & $M H_{2}^{1}$ & & & $M H_{2}^{2}$ & & & $\mathrm{MH}_{2}^{3}$ & & & $M H_{2}^{4}$ & & & $M H_{2}^{5}$ & \\
\hline$|\dot{\Delta}|$ & $d$ & $E_{I}^{l}$ & \#UAVs & time & energy & \#UAVs & time & energy & \#UAVs & time & energy & \#UAVs & time & energy & \#UAVs & time & energy \\
\hline 10 & 20 & 300 & 17 & 1.92 & 6507.50 & 19 & 2.53 & 7302.50 & 20 & 2.48 & 7635.00 & 21 & 2.46 & 8050.00 & 17 & 2.37 & 6560.00 \\
\hline 10 & 20 & 600 & 16 & 1.37 & 7910.00 & 15 & 1.65 & 8240.00 & 15 & 1.51 & 7572.50 & 16 & 1.78 & 8055.00 & 12 & 1.26 & 6370.00 \\
\hline 10 & 20 & 900 & 13 & 0.90 & 7890.00 & 13 & 1.26 & 7932.50 & 13 & 0.76 & 8125.00 & 14 & 1.01 & 8382.50 & 11 & 1.08 & 6632.50 \\
\hline 15 & 20 & 300 & 21 & 3.42 & 7952.50 & 21 & 3.54 & 8490.00 & 24 & 3.79 & 8850.00 & 22 & 3.78 & 8725.00 & 23 & 4.48 & 8867.50 \\
\hline 15 & 20 & 600 & 18 & 2.64 & 8152.50 & 18 & 3.12 & 8667.50 & 20 & 3.37 & 8760.00 & 17 & 3.24 & 7980.00 & 18 & 3.79 & 8590.00 \\
\hline 15 & 20 & 900 & 12 & 2.18 & 7952.50 & 13 & 2.18 & 9677.50 & 14 & 1.92 & 9235.00 & 13 & 2.46 & 8215.00 & 13 & 2.23 & 8402.50 \\
\hline 20 & 20 & 300 & 30 & 5.19 & 11265.50 & 29 & 6.02 & 11468.00 & 26 & 5.57 & 9833.00 & 30 & 5.23 & 11980.50 & 31 & 6.15 & 12350.50 \\
\hline 20 & 20 & 600 & 24 & 4.18 & 11710.00 & 24 & 4.20 & 11457.50 & 23 & 3.76 & 11063.00 & 21 & 4.84 & 10245.50 & 22 & 4.52 & 10608.00 \\
\hline 20 & 20 & 900 & 18 & 3.84 & 11910.50 & 18 & 3.45 & 12405.00 & 17 & 3.01 & 11625.50 & 19 & 3.43 & 12590.50 & 18 & 6.13 & 11990.50 \\
\hline 25 & 20 & 300 & 34 & 12.71 & 11799.00 & 32 & 12.32 & 12270.50 & 29 & 12.59 & 10741.50 & 33 & 13.48 & 11935.50 & 34 & 15.93 & 11351.50 \\
\hline 25 & 20 & 600 & 28 & 11.09 & 12549.00 & 26 & 11.81 & 11808.50 & 23 & 12.56 & 11196.50 & 27 & 10.39 & 12354.00 & 27 & 12.60 & 11879.00 \\
\hline 25 & 20 & 900 & 18 & 6.36 & 11646.50 & 21 & 6.77 & 13427.00 & 20 & 7.21 & 11780.50 & 20 & 7.50 & 11785.50 & 20 & 8.83 & 11425.50 \\
\hline 30 & 20 & 300 & 43 & 16.71 & 17410.00 & 41 & 17.80 & 16880.00 & 37 & 16.58 & 15760.00 & 34 & 15.99 & 14392.50 & 39 & 20.30 & 15782.50 \\
\hline 30 & 20 & 600 & 27 & 14.60 & 14670.00 & 33 & 15.05 & 17725.00 & 35 & 13.34 & 17975.00 & 25 & 16.05 & 13492.50 & 30 & 18.70 & 15685.00 \\
\hline 30 & 20 & 900 & 26 & 12.34 & 15595.00 & 27 & 14.02 & 17185.00 & 24 & $\begin{array}{r}10.04 \\
8.42\end{array}$ & 15025.00 & 24 & 14.70 & 14302.50 & 24 & $\begin{array}{l}10.10 \\
13.99\end{array}$ & 15322.50 \\
\hline 10 & 10 & 300 & 17 & 8.89 & 6350.00 & 17 & 7.96 & 6065.00 & 17 & 9.86 & 6812.50 & 18 & 7.57 & 6692.50 & 15 & 8.42 & 5807.50 \\
\hline 10 & 10 & 600 & 11 & 3.62 & 5510.00 & 11 & 3.95 & 5980.00 & 11 & $\begin{array}{l}9.00 \\
3.26\end{array}$ & $\begin{array}{l}6265.00 \\
6260\end{array}$ & 12 & $\begin{array}{l}.089 \\
4.59\end{array}$ & 6422.50 & $\begin{array}{r}10 \\
9\end{array}$ & $\begin{array}{l}0.42 \\
4.45\end{array}$ & 4662.50 \\
\hline 10 & 10 & 900 & 9 & 2.78 & 6515.00 & 10 & 3.65 & 7002.50 & 9 & 2.64 & 6572.50 & 10 & 3.34 & 7107.50 & 8 & 4.71 & 5765.00 \\
\hline 15 & 10 & 300 & 22 & 19.19 & 8162.00 & 24 & 21.01 & 9310.00 & 22 & 18.80 & 8162.00 & 20 & 22.32 & 7875.00 & 21 & 24.80 & 6957.50 \\
\hline 15 & 10 & 600 & 15 & 10.31 & 6634.00 & 16 & 11.82 & 7802.50 & 14 & 8.85 & 6311.50 & 15 & 17.88 & 7410.00 & 15 & 14.63 & 6757.00 \\
\hline 15 & 10 & 900 & 14 & 9.11 & 8810.00 & 12 & 12.84 & 8175.00 & 14 & 10.55 & 8187.50 & 12 & 9.03 & 8385.00 & 14 & 11.48 & 9700.00 \\
\hline 20 & 10 & 300 & 26 & 41.84 & 10814.00 & 31 & 45.51 & 11712.50 & 25 & 42.71 & 10359.00 & 29 & 42.34 & 11375.00 & 28 & 34.46 & 12207.00 \\
\hline 20 & 10 & 600 & 23 & 20.50 & 11954.00 & 22 & 37.16 & 11630.00 & 21 & 29.58 & 10714.00 & 20 & 40.12 & 10489.00 & 20 & 29.23 & 10395.00 \\
\hline 20 & 10 & 900 & 18 & 19.67 & 12100.00 & 17 & 25.82 & 11745.00 & 18 & 26.25 & 10962.50 & 20 & 19.06 & 14645.00 & 16 & 16.41 & 10805.00 \\
\hline 25 & 10 & 300 & 39 & 97.19 & 14301.50 & 33 & 85.18 & 14283.00 & 36 & 103.18 & 13461.00 & 37 & $\begin{array}{r}102.04 \\
\end{array}$ & 14353.50 & 34 & $\begin{array}{l}89.76 \\
89.76\end{array}$ & 12596.50 \\
\hline 25 & 10 & 600 & 30 & 55.47 & 15847.00 & 32 & 50.64 & 16431.00 & 30 & 42.51 & 15400.00 & 27 & 85.13 & 14106.50 & 27 & 72.98 & 13261.50 \\
\hline 25 & 10 & 900 & 21 & 29.36 & 14127.50 & 21 & 59.30 & 14024.00 & 23 & 39.76 & 15196.00 & 21 & 30.51 & 15081.00 & 22 & 55.85 & 15220.00 \\
\hline $\begin{array}{l}20 \\
30\end{array}$ & 10 & 300 & $\begin{array}{l}21 \\
39\end{array}$ & 146.14 & 14632.50 & $\begin{array}{l}21 \\
28\end{array}$ & $\begin{array}{r}59.50 \\
126.53\end{array}$ & $\begin{array}{l}14024.00 \\
11205.00\end{array}$ & $\begin{array}{l}23 \\
38\end{array}$ & $\begin{array}{r}39.10 \\
143.72\end{array}$ & $\begin{array}{l}151906.00 \\
1500600\end{array}$ & 41 & $\begin{array}{r}30.01 \\
164.43\end{array}$ & 16455.00 & 42 & $\begin{array}{r}53.80 \\
188.31\end{array}$ & $\begin{array}{l}15220.00 \\
15575.00\end{array}$ \\
\hline $\begin{array}{l}30 \\
30\end{array}$ & 10 & 600 & $\begin{array}{l}39 \\
30\end{array}$ & $\begin{array}{r}416.14 \\
71.89\end{array}$ & $\begin{array}{l}14632.50 \\
14693.50\end{array}$ & $\begin{array}{l}28 \\
27\end{array}$ & $\begin{array}{l}126.53 \\
126.25\end{array}$ & $\begin{array}{l}112000.00 \\
13000\end{array}$ & $\begin{array}{l}58 \\
31\end{array}$ & $\begin{array}{r}143.12 \\
53.65\end{array}$ & 15310.00 & $\begin{array}{l}41 \\
23\end{array}$ & $\begin{array}{r}104.43 \\
83.87\end{array}$ & 11421.00 & 26 & $\begin{array}{r}180.31 \\
81.03\end{array}$ & $\begin{array}{l}15575.00 \\
13260.00\end{array}$ \\
\hline 30 & 10 & 900 & 23 & 44.68 & 14827.50 & 19 & 58.14 & 13595.00 & 20 & 43.27 & 13125.00 & 21 & $\begin{array}{l}54.44 \\
54.01\end{array}$ & 13707.50 & 22 & $\begin{array}{l}4.1 .03 \\
44.13\end{array}$ & 14707.50 \\
\hline 10 & 5 & 300 & 15 & $\begin{array}{l}44.00 \\
44.52\end{array}$ & 6412.50 & 16 & $\begin{array}{l}30.14 \\
49.30\end{array}$ & $\begin{array}{r}6627.50 \\
662.00\end{array}$ & 18 & 44.15 & $\begin{array}{r}131252.00 \\
7992.50\end{array}$ & 15 & $\begin{array}{l}45.04 \\
45.04\end{array}$ & 5554.50 & 18 & 43.81 & $\begin{array}{r}7319.00 \\
73190\end{array}$ \\
\hline 10 & 5 & 600 & 16 & 38.30 & 7592.00 & 13 & 40.92 & 6729.50 & 13 & 37.74 & 6622.00 & 15 & 34.55 & 7151.00 & 13 & 43.66 & 6429.50 \\
\hline 10 & 5 & 900 & 9 & 23.04 & 6930.00 & 10 & 27.92 & 6582.50 & 9 & 23.06 & 6456.50 & 9 & 23.51 & 6730.00 & 9 & $\begin{array}{l}36.00 \\
36.43\end{array}$ & 6564.00 \\
\hline 15 & 5 & 300 & 20 & 118.50 & 7569.00 & 22 & 155.08 & 8234.50 & 19 & 114.50 & 6901.50 & 26 & 154.74 & 9444.00 & 21 & 168.82 & 7629.00 \\
\hline 15 & 5 & 600 & 17 & 76.91 & 8661.50 & 15 & 80.71 & 7872.00 & 17 & 76.46 & 8279.50 & 18 & 86.08 & 8321.50 & 17 & 93.99 & 8422.00 \\
\hline 15 & 5 & 900 & 13 & 67.60 & 8755.00 & 14 & 68.00 & 9064.50 & 13 & 64.32 & 8650.00 & 13 & 66.04 & 8728.50 & 13 & 80.86 & 8997.50 \\
\hline 20 & 5 & 300 & 28 & 192.82 & 12315.50 & 29 & 251.96 & 11109.50 & 25 & 229.85 & 10958.00 & 29 & 227.96 & 12520.50 & 23 & 228.90 & 10250.50 \\
\hline 20 & 5 & 600 & 25 & 156.98 & 11600.50 & 21 & 154.75 & 10703.50 & 22 & 151.57 & 10624.50 & 23 & 172.85 & 11561.50 & 22 & 173.02 & 11474.50 \\
\hline 20 & 5 & 900 & 16 & 136.33 & 10403.00 & 17 & 135.94 & 10733.00 & 15 & 121.52 & 10360.50 & 19 & 144.22 & 13837.50 & 19 & 145.25 & 13615.00 \\
\hline 25 & 5 & 300 & 32 & 412.44 & 12131.50 & 32 & 451.28 & 13417.50 & 32 & 445.30 & 12939.50 & 31 & 433.59 & 11715.00 & 35 & 441.03 & 13926.50 \\
\hline 25 & 5 & 600 & 26 & 341.80 & 12645.00 & 26 & 392.51 & 12732.50 & 26 & 319.90 & 14347.00 & 30 & 326.37 & 14831.00 & 27 & 350.67 & 12884.00 \\
\hline $\begin{array}{l}25 \\
25\end{array}$ & $\begin{array}{l}5 \\
5\end{array}$ & 900 & $\begin{array}{l}20 \\
20\end{array}$ & $\begin{array}{l}241.80 \\
248.38\end{array}$ & 14588. & $\begin{array}{l}20 \\
21\end{array}$ & $\begin{array}{l}276.25 \\
276.51\end{array}$ & $\begin{array}{l}12732.00 \\
15293.00\end{array}$ & $\begin{array}{l}20 \\
19\end{array}$ & $\begin{array}{l}319.90 \\
287.76\end{array}$ & 14094.50 & 20 & $\begin{array}{l}320.31 \\
310.33\end{array}$ & $\begin{array}{l}14831.00 \\
14627.00\end{array}$ & 19 & $\begin{array}{l}350.68 \\
342.84\end{array}$ & $\begin{array}{l}12804.00 \\
13179.00\end{array}$ \\
\hline 30 & 5 & 300 & 42 & 706.08 & 15876.00 & 37 & 663.71 & 15168.00 & 41 & 698.34 & 14662.50 & 38 & 696.01 & 16580.00 & 36 & 587.76 & 14024.00 \\
\hline 30 & 5 & 600 & 30 & 488.92 & 15841.50 & 30 & 517.46 & 14841.50 & 32 & 427.54 & 16184.50 & 28 & 651.27 & 15070.50 & 28 & 563.30 & 14252.00 \\
\hline 30 & 5 & 900 & 27 & 474.12 & 18442.00 & 23 & 483.10 & 15967.50 & 23 & 384,82 & 15892,50 & 24 & 581,62 & 17272,00 & 23 & 395,77 & 15972,50 \\
\hline
\end{tabular}

Table A.3: Computational results obtained with the MIP-based heuristics when solving model $M_{2}$. 


\begin{tabular}{|c|c|c|c|c|c|c|c|c|c|c|c|c|c|c|c|c|c|}
\hline & & & & $M H_{c}^{1}$ & & & $M H_{c}^{2}$ & & & $M H_{c}^{3}$ & & & $M H_{c}^{4}$ & & & $M H_{c}^{5}$ & \\
\hline$|\dot{\Delta}|$ & $d$ & $E_{I}^{l}$ & cost & time & energy & cost & time & energy & cost & time & energy & cost & time & energy & cost & time & energy \\
\hline 10 & 20 & 300 & 15 & 3,48 & 7707.50 & 13 & 2,73 & 6400,00 & 14 & 2,37 & 7210,00 & 14 & 2.76 & 7282,50 & 13 & 2,59 & 6762.50 \\
\hline 10 & 20 & 600 & 10 & 1,61 & 7542,50 & 9 & 1.39 & 8012,50 & 10 & 1,67 & 7637,50 & 10 & 1,86 & 7782,50 & 8 & 1,17 & 7235000 \\
\hline 10 & 20 & 900 & 4 & 1,03 & 7495,00 & 4 & 1.33 & 8030.00 & 4 & 0,72 & 7730.00 & 5 & $\begin{array}{l}1,00 \\
1.26\end{array}$ & 861750 & 3 & 1.08 & 7277.50 \\
\hline 15 & 20 & 300 & 17 & 6,04 & 7827,50 & 19 & 5,74 & 8502,50 & 21 & 5,41 & 9645,00 & 18 & $\begin{array}{l}1,20 \\
5,40\end{array}$ & 8142,50 & 19 & 5,68 & 8660,00 \\
\hline 15 & 20 & 600 & 7 & 3,96 & 8552,50 & 7 & 3,48 & 8405,00 & 7 & $\begin{array}{l}\quad, 41 \\
3,62\end{array}$ & 8842,50 & 7 & 3,40 & 8660,00 & 7 & 4,65 & 8755,00 \\
\hline 15 & 20 & 900 & 1 & $\begin{array}{l}2,07 \\
2,07\end{array}$ & 9480,00 & 1 & $\begin{array}{l}2,40 \\
2,34\end{array}$ & 9112,50 & 1 & $\begin{array}{l}1,65 \\
1,65\end{array}$ & 9250,00 & 1 & $\begin{array}{l}{ }_{2,40}, 32 \\
2,32\end{array}$ & 9590,00 & 1 & 1,92 & 8452,50 \\
\hline 20 & 20 & 300 & 25 & 7,71 & 11813,00 & 24 & 7,61 & 10758,00 & 23 & 6,40 & 11173,00 & 23 & 7,21 & 11080,50 & 22 & 8,22 & 10408,00 \\
\hline 20 & 20 & 600 & 10 & 5,34 & 11648,00 & 11 & 5,62 & 10910,50 & 10 & 4,23 & 12692,50 & 11 & 5,85 & 11673,00 & 9 & 4,12 & 11575,50 \\
\hline 20 & 20 & 900 & 2 & 3,87 & 11750,50 & 2 & 3,81 & 12420,50 & 2 & 3,07 & 12815,50 & 2 & 3,71 & 13073,00 & 3 & 4,12 & 12695,50 \\
\hline 25 & 20 & 300 & 27 & 26,11 & 12626,50 & 26 & 24,71 & 12329,50 & 23 & 21,00 & 10990,50 & 24 & 21,00 & 11492,00 & 25 & 22,48 & 11349,00 \\
\hline 25 & 20 & 600 & 12 & 16,04 & 13116,50 & 11 & 12,90 & 13772,00 & 9 & 15,33 & 11650,50 & 10 & 11,03 & 12370,50 & 10 & 11,61 & 10901,50 \\
\hline 25 & 20 & 900 & 1 & 5,07 & 12841,50 & 1 & 6,47 & 14048,00 & 1 & 7,08 & 12829,00 & 1 & 8,03 & 13093,00 & 1 & $\begin{array}{r}7,74 \\
7,74\end{array}$ & 13209,00 \\
\hline 30 & 20 & 300 & 35 & 30,01 & 16447,50 & 36 & 30,89 & 16460,00 & 36 & 29,37 & 17037,50 & 34 & 26,83 & 15047,50 & 33 & 28,44 & 15967,50 \\
\hline 30 & 20 & 600 & 22 & 21,51 & 17855,00 & 23 & $\begin{array}{l}24,69 \\
24,69\end{array}$ & 16660,00 & 20 & 18,52 & 16715,00 & 23 & 22,95 & 18112,50 & 21 & 1850 & 1693000 \\
\hline 30 & 20 & 900 & 6 & $\begin{array}{l}19,33 \\
19,33\end{array}$ & 19507,50 & 6 & $\begin{array}{l}4,09 \\
14,93\end{array}$ & 19347,50 & $\begin{array}{r}20 \\
7\end{array}$ & $\begin{array}{r}10,02 \\
9,95\end{array}$ & 20735,00 & 7 & 20,28 & 20670,00 & $\begin{array}{r}21 \\
7\end{array}$ & $\begin{array}{l}10,00 \\
14,31\end{array}$ & 19725,00 \\
\hline 10 & 10 & 300 & 12 & 16,18 & 6295,00 & 12 & 15,43 & $\begin{array}{r}19041,00 \\
5797,50\end{array}$ & 11 & $\begin{array}{r}9,90 \\
12,57\end{array}$ & 5400,00 & 12 & $\begin{array}{l}24,20 \\
14.27\end{array}$ & 6065,00 & 12 & $\begin{array}{l}15,01 \\
15,15\end{array}$ & 5717,50 \\
\hline $\begin{array}{l}10 \\
10\end{array}$ & $\begin{array}{l}10 \\
10\end{array}$ & $\begin{array}{l}300 \\
600\end{array}$ & $\begin{array}{r}12 \\
2\end{array}$ & $\begin{array}{r}16,18 \\
3,79\end{array}$ & $\begin{array}{l}6295,00 \\
5722,50\end{array}$ & $\begin{array}{r}12 \\
2\end{array}$ & $\begin{array}{r}15,43 \\
7,53\end{array}$ & $\begin{array}{l}5797,50 \\
6142,50\end{array}$ & $\begin{array}{r}11 \\
2\end{array}$ & $\begin{array}{r}12,57 \\
3,79\end{array}$ & $\begin{array}{l}5400,00 \\
6247,50\end{array}$ & $\begin{array}{r}12 \\
2\end{array}$ & $\begin{array}{r}14,27 \\
7,61\end{array}$ & $\begin{array}{l}60655,00 \\
5965,00\end{array}$ & $\begin{array}{r}12 \\
2\end{array}$ & $\begin{array}{r}15,15 \\
5,44\end{array}$ & $\begin{array}{l}5717,50 \\
5952,50\end{array}$ \\
\hline 10 & 10 & 900 & 0 & 2,95 & 6747,50 & 0 & 3,03 & 8035,00 & 0 & $\begin{array}{l}3,09 \\
3,04\end{array}$ & $\begin{array}{l}624,50 \\
6735,00\end{array}$ & $\begin{array}{l}2 \\
0\end{array}$ & $\begin{array}{l}2,61 \\
2,71\end{array}$ & $\begin{array}{l}6725,00 \\
6725,00\end{array}$ & 0 & $\begin{array}{l}5,44 \\
3,31\end{array}$ & $\begin{array}{l}5932,00 \\
6770,00\end{array}$ \\
\hline 15 & 10 & 300 & 13 & $\begin{array}{l}2,90 \\
32,68\end{array}$ & 6884,00 & 13 & $\begin{array}{r}3,03 \\
38,41\end{array}$ & 7084,00 & $\begin{array}{r}0 \\
13\end{array}$ & $\begin{array}{r}3,04 \\
38,66\end{array}$ & $\begin{array}{l}6.35,00 \\
6564,00\end{array}$ & 13 & $\begin{array}{r}2,71 \\
45,55\end{array}$ & $\begin{array}{l}6,25,00 \\
7376,50\end{array}$ & $\begin{array}{r}0 \\
13\end{array}$ & $\begin{array}{r}3,31 \\
52,49\end{array}$ & $\begin{array}{l}6770,00 \\
6862,00\end{array}$ \\
\hline $\begin{array}{l}15 \\
15\end{array}$ & 10 & $\begin{array}{l}300 \\
600\end{array}$ & $\begin{array}{r}13 \\
2\end{array}$ & $\begin{array}{l}32,68 \\
11,14\end{array}$ & $\begin{array}{l}7444,00 \\
744,00\end{array}$ & $\begin{array}{r}13 \\
2\end{array}$ & $\begin{array}{l}36,41 \\
16,77\end{array}$ & 7642,00 & $\begin{array}{r}13 \\
2\end{array}$ & $\begin{array}{l}38,60 \\
11,62\end{array}$ & $\begin{array}{l}\text { D.84, } \\
7179,00\end{array}$ & $\begin{array}{r}13 \\
2\end{array}$ & $\begin{array}{l}45,50 \\
19,19\end{array}$ & $\begin{array}{l}7327,00 \\
7327,00\end{array}$ & $\begin{array}{r}13 \\
2\end{array}$ & $\begin{array}{l}52,49 \\
20,22\end{array}$ & 6834,50 \\
\hline 15 & 10 & 900 & 0 & $\begin{array}{r}7,89 \\
7,89\end{array}$ & 10040,00 & 0 & 10,16 & 8620,00 & 0 & 9,77 & 10435,00 & 0 & $\begin{array}{l}19,19 \\
11,95\end{array}$ & 10115,00 & 0 & $\begin{array}{r}20,22 \\
8,95\end{array}$ & 10430,00 \\
\hline 20 & 10 & 300 & 20 & 84,05 & 10383,50 & 21 & 82,70 & 11333,50 & 20 & 87,88 & 11403,50 & 20 & 88,89 & 10921,00 & 20 & 88,34 & 10558,50 \\
\hline 20 & 10 & 600 & 6 & 26,07 & 11659,50 & 6 & 36,97 & 12187,00 & 6 & $\begin{array}{l}27,72 \\
27,00\end{array}$ & 11937,00 & 6 & 147,73 & 12016,00 & 6 & $\begin{array}{l}40,22 \\
40,22\end{array}$ & 12121,00 \\
\hline 20 & 10 & 900 & 0 & 10,81 & 14174,50 & 0 & 16,75 & 14291,50 & 0 & 13,84 & 14627,50 & 1 & 19,91 & 14860,00 & 0 & 11,97 & 15297,50 \\
\hline 25 & 10 & 300 & 25 & 205,42 & 13790,50 & 27 & 186,25 & 13720,50 & 27 & 217,50 & 12823,00 & 28 & 215,00 & 14797,00 & 25 & 206.70 & 12047,00 \\
\hline 25 & 10 & 600 & 8 & 90,46 & 13720,50 & 9 & 84,63 & 14774,50 & 9 & 57.00 & 14235,00 & 8 & 193,58 & 13442,50 & 10 & 110.32 & 13697,00 \\
\hline 25 & 10 & 900 & 0 & 23,84 & 15554,00 & 0 & 29,28 & 15537,00 & 0 & 27,16 & 16239,00 & 0 & 50,72 & 15301,00 & 0 & 27,55 & 14807,50 \\
\hline 30 & 10 & 300 & 27 & 3314,54 & 13836,00 & 26 & $\begin{array}{r}29,20 \\
395,98\end{array}$ & 13385,00 & 29 & 347,96 & 14778,50 & 25 & 383,00 & 12918,50 & 26 & 338,80 & 13738,50 \\
\hline 30 & 10 & 600 & 6 & $\begin{array}{r}111,24 \\
111,24\end{array}$ & 16751,500 & 20 & 97,42 & 14512,50 & 29 & $\begin{aligned} & 63,09 \\
& 63,09\end{aligned}$ & 16471,00 & 6 & 291,29 & 14823,50 & 6 & $\begin{array}{l}80,17 \\
80,17\end{array}$ & 16376,00 \\
\hline 30 & 10 & 900 & 0 & $\begin{array}{r}11,24 \\
33,04\end{array}$ & 17675,00 & 0 & $\begin{array}{l}91,42 \\
37,69\end{array}$ & 17742,500 & 0 & $\begin{array}{l}0.5,09 \\
38,61\end{array}$ & 16710,00 & 0 & $\begin{array}{r}291,29 \\
51,64\end{array}$ & 16590,00 & 0 & 48,84 & 15647,50 \\
\hline $\begin{array}{l}30 \\
10\end{array}$ & $\begin{array}{c}10 \\
5\end{array}$ & $\begin{array}{l}900 \\
300\end{array}$ & $\begin{array}{r}0 \\
15\end{array}$ & $\begin{array}{l}33,04 \\
95,11\end{array}$ & $\begin{array}{r}17675,00 \\
7027,50\end{array}$ & $\begin{array}{r}0 \\
15\end{array}$ & $\begin{array}{r}37,69 \\
125,38\end{array}$ & $\begin{array}{r}17742,50 \\
6519,00\end{array}$ & $\begin{array}{r}0 \\
15\end{array}$ & $\begin{array}{r}38,61 \\
111,76\end{array}$ & $\begin{array}{r}16710,00 \\
6638,50\end{array}$ & $\begin{array}{l}0 \\
15\end{array}$ & $\begin{array}{r}51,64 \\
129,03\end{array}$ & $\begin{array}{r}16590,00 \\
6193,50\end{array}$ & $\begin{array}{r}0 \\
13\end{array}$ & $\begin{array}{r}48,84 \\
160,49\end{array}$ & $\begin{array}{r}15647,50 \\
5917,00\end{array}$ \\
\hline 10 & 5 & 600 & 6 & 101,65 & 6547.00 & 6 & 131,27 & 6508,50 & 6 & 68 & 7092 & 6 & 162,94 & 679 & 6 & 82,95 & 6388,50 \\
\hline 10 & $\begin{array}{l}0 \\
5\end{array}$ & 900 & 0 & $\begin{array}{r}101,00 \\
25,57\end{array}$ & 6474,50 & 0 & $\begin{array}{r}101,27 \\
33,29\end{array}$ & 6323,50 & 0 & $\begin{array}{l}0,09 \\
35,85\end{array}$ & 614 & 0 & $\begin{array}{r}102,94 \\
33,93\end{array}$ & 673 & 0 & $\begin{array}{l}8,90 \\
38,19\end{array}$ & $\begin{array}{l}0300,00 \\
7690,00\end{array}$ \\
\hline 15 & $\begin{array}{l}5 \\
5\end{array}$ & 300 & 15 & $\begin{array}{r}259,76 \\
599\end{array}$ & $\begin{array}{l}047,50 \\
7560,50\end{array}$ & 15 & $\begin{array}{r}33,29 \\
695,62\end{array}$ & $\begin{array}{l}0.3203,00 \\
7803,00\end{array}$ & 15 & $\begin{array}{r}35,83 \\
419,07\end{array}$ & $\begin{array}{l}1140,00 \\
7520,50\end{array}$ & 15 & $\begin{array}{r}33,93 \\
589,71\end{array}$ & 7055,50 & 14 & $\begin{array}{r}38,19 \\
724,02\end{array}$ & 7567,00 \\
\hline 15 & 5 & 600 & 3 & 64,55 & 7793,00 & $\begin{array}{r}15 \\
3\end{array}$ & $\begin{array}{l}095,22 \\
104,22\end{array}$ & 7283,00 & $\begin{array}{r}15 \\
3\end{array}$ & $\begin{array}{l}419,01 \\
105,14\end{array}$ & 7283,00 & $\begin{array}{r}15 \\
3\end{array}$ & $\begin{array}{l}389,11 \\
181,24\end{array}$ & 7000,50 & $\begin{array}{r}14 \\
3\end{array}$ & $\begin{array}{l}124,02 \\
130,68\end{array}$ & 7283,00 \\
\hline $\begin{array}{l}15 \\
15\end{array}$ & $\begin{array}{l}5 \\
5\end{array}$ & $\begin{array}{l}600 \\
900\end{array}$ & 0 & $\begin{array}{l}4,55 \\
45,41\end{array}$ & 9228,00 & 0 & $\begin{array}{r}104,22 \\
96,03\end{array}$ & 9604,00 & $\begin{array}{l}3 \\
0\end{array}$ & $\begin{array}{l}105,14 \\
111,49\end{array}$ & 8844,00 & $\begin{array}{l}3 \\
0\end{array}$ & $\begin{array}{r}181,24 \\
97,89\end{array}$ & 9018,50 & 0 & $\begin{array}{l}130,68 \\
108,69\end{array}$ & 9507,00 \\
\hline 20 & 5 & 300 & 20 & 583,72 & 10519,50 & 20 & 645,08 & 11320,50 & 19 & 636,16 & 10394,50 & 20 & 599,06 & 10949,00 & 20 & 810,92 & 10577,50 \\
\hline 20 & 5 & 600 & 6 & 667,89 & 11140,00 & 6 & 865,28 & 11692,00 & 6 & 415,82 & 11340,50 & 6 & 716,48 & 11617,50 & 6 & 511,45 & 10921,50 \\
\hline 20 & 5 & 900 & 0 & 199,01 & 13306,00 & 0 & $\begin{array}{l}000,20 \\
169,92\end{array}$ & 12292,50 & 0 & 170,84 & 13698,00 & 0 & 182,72 & 13739,00 & 0 & 151.98 & 13381,50 \\
\hline 25 & 5 & 300 & 27 & 1412,50 & 12590,50 & 27 & 1827,50 & 12293,50 & 27 & $\begin{array}{r}1658,73 \\
16,04\end{array}$ & 13042,00 & 26 & 1532,40 & 12483,00 & 24 & $\begin{array}{r}1378,64 \\
1378\end{array}$ & 12836,00 \\
\hline 25 & 5 & 600 & 11 & 1455.55 & 12752,50 & 10 & 150399 & 1230300 & 11 & 929.13 & 13826,00 & 10 & 1450.08 & 13090.00 & 11 & 106976 & 1447500 \\
\hline 25 & 5 & 900 & 0 & 378,43 & 15473,50 & 0 & 413,18 & 13864,50 & 0 & 406,48 & $\begin{array}{l}10020,00 \\
16129,00\end{array}$ & 0 & $\begin{array}{r}1400,00 \\
432,92\end{array}$ & 14834,00 & $\begin{array}{r}11 \\
0\end{array}$ & 37306 & 14358,00 \\
\hline $\begin{array}{l}25 \\
30\end{array}$ & $\begin{array}{l}5 \\
5\end{array}$ & $\begin{array}{l}300 \\
300\end{array}$ & 31 & $\begin{array}{r}37,43 \\
2217,02\end{array}$ & $\begin{array}{l}15473,50 \\
15334,50\end{array}$ & 27 & $\begin{array}{r}4134,18 \\
1734,45\end{array}$ & $\begin{array}{l}13864,50 \\
13110,00\end{array}$ & $\begin{array}{r}0 \\
29\end{array}$ & $\begin{array}{r}406,48 \\
2062,89\end{array}$ & $\begin{array}{l}16129,00 \\
14351,00\end{array}$ & $\begin{array}{l}0 \\
32\end{array}$ & $\begin{array}{r}432,92 \\
2044,28\end{array}$ & $\begin{array}{l}14834,00 \\
15762,50\end{array}$ & 31 & $\begin{array}{r}37,06 \\
2445,78\end{array}$ & $\begin{array}{l}14358,00 \\
15194,00\end{array}$ \\
\hline $\begin{array}{l}30 \\
30\end{array}$ & $\begin{array}{l}5 \\
5\end{array}$ & $\begin{array}{l}300 \\
600\end{array}$ & $\begin{array}{l}31 \\
10\end{array}$ & $\begin{array}{l}2217,02 \\
1497,38\end{array}$ & $\begin{array}{l}15334,50 \\
17137,00\end{array}$ & $\begin{array}{r}27 \\
9\end{array}$ & $\begin{array}{l}1734,45 \\
1101,54\end{array}$ & $\begin{array}{l}13110,00 \\
16287,00\end{array}$ & $\begin{array}{l}29 \\
10\end{array}$ & $\begin{array}{r}2062,89 \\
829,60\end{array}$ & $\begin{array}{l}14351,00 \\
17184,50\end{array}$ & $\begin{array}{r}32 \\
8\end{array}$ & $\begin{array}{l}2044,28 \\
1447,94\end{array}$ & $\begin{array}{l}15762,50 \\
14510,50\end{array}$ & $\begin{array}{r}31 \\
9\end{array}$ & $\begin{array}{l}244,78 \\
1147,51\end{array}$ & $\begin{array}{l}15194,00 \\
16007,00\end{array}$ \\
\hline $\begin{array}{l}30 \\
30\end{array}$ & 5 & 900 & $\begin{array}{r}10 \\
0\end{array}$ & $\begin{array}{r}149,38 \\
567.64\end{array}$ & 18966.00 & 0 & $\begin{array}{r}1101,54 \\
53786\end{array}$ & $\begin{array}{l}10281,00 \\
19711,50\end{array}$ & 0 & $\begin{array}{l}829,60 \\
496,83\end{array}$ & 18083,00 & $\begin{array}{l}8 \\
0\end{array}$ & $\begin{array}{r}144,94 \\
531,54\end{array}$ & 18137,50 & 0 & $\begin{array}{r}114,01 \\
549,93\end{array}$ & 18882,00 \\
\hline
\end{tabular}

Table A.4: Computational results obtained with the MIP-based heuristics when solving model $M_{c}$. 


\section{References}

[1] A. Ahmadzadeh, G. Buchman, P. Cheng, A. Jadbabaie, J. Keller, V. Kumar, and G. Pappas. Cooperative control of uavs for search and coverage. In Proceedings of the Conference on Unmanned Systems (AUVSI), pages 1-14, 2006.

[2] J.F. Bérubé, M. Gendreau, and J.Y. Potvin. An exact $\epsilon$-constraint method for bi-objective combinatorial optimization problems: Application to the traveling salesman problem with profits. European Journal of Operational Research, 194:39-50, 2009.

[3] A. P. Brown, K. J. Sullivan, and D. J. Miller. Feature-aided multiple target tracking in the image plane. In Intelligent Computing: Theory and Applications IV, volume 6229, pages 62290Q-62290Q-12, 2006.

[4] F. Bullo, E. Frazzoli, M. Pavone, K. Savla, and S. L. Smith. Dynamic vehicle routing for robotic systems. IEEE proceedings, 99(9):1482-1504, 2011.

[5] G. Cannata and A. Sgorbissa. A minimalist algorithm for multirobot continuous coverage. Robotics, IEEE Transactions on, 27(2):297-312, 2011.

[6] W. Chung, V. Crespi, G. Cybenko, and A. Jordan. Distributed sensing and uav scheduling for surveillance and tracking of unidentifiable targets. In Proc. SPIE, volume 5778, pages 226-235, 2005.

[7] L. Di Puglia Pugliese and F. Guerriero. A reference point approach for the resource constrained shortest path problems. Transport Science, 47(2):247-265, 2013.

[8] L. Grandinetti, F. Guerriero, D. Laganá, and O. Pisacane. An optimization-based heuristic for the multi-objective undirected capacitated arc routing problem. Computers $\&$ Operations Research, 39(10):2300 - 2309, 2012.

[9] F. Guerriero, R. Surace, V. Loscrí, and E. Natalizio. A multi-objective approach for unmanned aerial vehicle routing problem with soft time windows constraints. Applied Mathematical Modelling, 38(3):839-852, 2014.

[10] Pascal Hentenryck, Russell Bent, and Eli Upfal. Online stochastic optimization under time constraints. Annals of Operations Research, 177(1):151-183, 2010.

[11] S. Hrabar. 3d path planning and stereo-based obstacle avoidance for rotorcraft uavs. In IEEE/RSJ International Conference on Intelligent Robots and Systems (IROS), pages 807$814,2008$.

[12] K. Jongrae and K. Yoonsoo. Moving ground target tracking in dense obstacle areas using. In the 17th IFAC World Congress, volume 17, pages 8552-8557, 2008.

[13] K. Mehlhorn and M. Ziegelmann. Resource constrained shortest paths. In $7^{\text {th }}$ Ann European Symp on Algorithms (ESA2000), LNCS 1879, pages 326-337, 2000. 
[14] M. Pavone, A. Arsie, E. Frazzoli, and F. Bullo. Distributed algorithms for environment partitioning in mobile robotic networks. IEEE Trans. on Automatic Control, 56(8):18341848, 2011.

[15] M. Pavone, K. Savla, and E. Frazzoli. Sharing the load. Robotics Automation Magazine, IEEE, 16(2):52-61, 2009.

[16] Y. Qi and Y. Zhao. Energy-efficient trajectories of unmanned aerial vehicles flying through thermals. Journal of Aerospace Engineering, 18(2):84-92, 2005.

[17] T. Razafindralambo, N. Mitton, A.C. Viana, M. Dias de Amorim, and K. Obraczka. Adaptive deployment for pervasive data gathering in connectivity-challenged environments. In The 8th IEEE International Conference on Pervasive Computing and Communications, pages 51-59, 2010.

[18] Matthew Ridley, Eric Nettleton, Ali Gktogan, Graham Brooker, Salah Sukkarieh, and HughF. Durrant-Whyte. Decentralised ground target tracking with heterogeneous sensing nodes on multiple uavs. In F. Zhao and L. Guibas, editors, Information Processing in Sensor Networks, volume 2634 of Lecture Notes in Computer Science, pages 545-565. Springer Berlin Heidelberg, 2003.

[19] C. Schumacher. Ground moving target engagement by cooperative uavs. In Proceedings of American Control Conference, pages 4502-4505, 2005.

[20] S. Simi, R. Kurup, and S. Rao. Distributed task allocation and coordination scheme for a multi-uav sensor network. In The 10th International Conference on Wireless and Optical Communications Networks, pages 1-5, 2013.

[21] A. Sinha, T. Kirubarajan, and Y. Bar-Shalom. Optimal cooperative placement of gmti uavs for ground target tracking. In Aerospace Conference, 2004. Proceedings. 2004 IEEE, volume 3, page 1868, 2004.

[22] P. Toth and D. Vigo. The Vehicle Routing Problem. Society for Industrial and Applied Mathematics, Philadelphia, PA, USA, 2001.

[23] L. Wang, H. Zhu, and L. Shen. Cooperative ground moving target standoff tracking using uavs. In The 2nd International Conference on Computer and Automation Engineering, volume 2, pages 377-382, 2010.

[24] Y. Watanabe, C. Lesire, A. Piquereau, P. Fabiani, M. Sanfourche, and G. Le Besnerais. The onera ressac unmanned autonomous helicopter: Visual air-to-ground target tracking in an urban environment. In American Helicopter Society 66th Annual Forum (AHS Forum), May 2010.

[25] A. Wierzbicki. Basic properties of scalarizing functionals for multiobjective optimization. Mathematische Operationsforschung und Statistik, s. Optimization, 8:55-60, 1977. 
[26] J. Yan, A.A. Minai, and M.M. Polycarpou. Cooperative real-time search and task allocation in uav teams. In Decision and Control, 2003. Proceedings. 42nd IEEE Conference on, volume 1, pages $7-12,2003$.

[27] M. Yongguo, L. Yung-Hsiang, Y.C. Hu, and C.S.G. Lee. A case study of mobile robot's energy consumption and conservation techniques. In Advanced Robotics, 2005. ICAR '05, volume 5778, pages 492-497, 2005.

[28] P. Zhan, D.W. Casbeer, and A.L. Swindlehurst. A centralized control algorithm for target tracking with uavs. In The 39th Asilomar Conference on Signals, Systems and Computers, pages 1148 - 1152, 28 - november 1, 2005.

[29] D. Zorbas, T. Razafindralambo, L. Di Puglia Pugliese, and F. Guerriero. Energy efficient mobile target tracking using flying drones. In The 4th International Conference on Ambient Systems, Networks and Technologies (ANT 2013), volume 19, pages 80 - 87, 2013. 